\title{
Multimode Analysis of Geometrically Nonlinear Transverse Free and Forced Vibrations of Tapered Beams
}

\author{
Issam El Hantati $\mathbb{C}^{1,2}$ Ahmed Adri $\mathbb{C}^{1},{ }^{1}$ Hatim Fakhreddine $\mathbb{C}^{1},{ }^{1}$ Said Rifai, ${ }^{1}$ \\ and Rhali Benamar ${ }^{3}$ \\ ${ }^{1}$ Laboratory of Mechanics Production and Industrial Engineering (LMPGI), High School of Technology (ESTC), \\ Hassan II University of Casablanca, Route d'ElJadida, Km 7, Oasis, Casablanca 8012, Morocco \\ ${ }^{2}$ Doctoral Studies Center of National High School of Electricity and Mechanics (ENSEM), Hassan II University of Casablanca, \\ Route d'ElJadida, Km 7, Oasis, Casablanca 8018, Morocco \\ ${ }^{3}$ Mohammed V University in Rabat, EMI-Rabat, LERSIM, B.P.765, Agdal, Rabat, Morocco \\ Correspondence should be addressed to Issam El Hantati; hantati.issam@gmail.com
}

Received 23 September 2021; Revised 20 December 2021; Accepted 6 January 2022; Published 30 January 2022

Academic Editor: Jie Yang

Copyright ( 2022 Issam El Hantati et al. This is an open access article distributed under the Creative Commons Attribution License, which permits unrestricted use, distribution, and reproduction in any medium, provided the original work is properly cited.

\begin{abstract}
In this study, the geometrically nonlinear free and forced vibrations of tapered beams are investigated on the basis of the EulerBernoulli beam theory and the von Karman geometric nonlinearity assumptions. The aim of the analysis is to determine tapered beams nonlinear frequencies and modes, and the associated stress distributions by means of bending moment diagrams. The linear problem is first solved. Then, to tackle the nonlinear problem, the displacement function is expanded as a series of the linear modes and the discrete expressions for the strain and kinetic energies are derived. Assuming a point excitation of the beam, the algebraic nonlinear system obtained based on Hamilton's principle is solved by an approximate method. The effect of the geometric nonlinearity in both the free and forced cases was illustrated and discussed and the effect of the variation of various tapered beam geometrical parameters. The effect of varying the excitation level was also examined.
\end{abstract}

\section{Introduction}

Very often, the beams used in mechanical, aeronautics, or robotics engineering are of a nonuniform cross section. The purpose of using nonuniform beams is to provide mechanical linkages to transmit force or motion, to reinforce an overall system, and to perform other technical functions. This type of beams is either presented by stepped or tapered beams. When such beams are subjected to high dynamic loads during operation, the control of their dynamics becomes of crucial importance in order to master their response and estimate properly their fatigue life. After a recent work concerned with stepped beams [1], the present paper examines tapered beams. Although many papers investigated this type of beams, most of them were restricted to linear analysis, but many have highlighted the limitations of the linear theory at large vibration amplitudes [2-4]. The occurrence of large displacements causes geometrical nonlinearities which have to be taken into account in order to avoid underestimation of strains and stresses. To overcome this difficulty, the nonlinear analysis proposed in the present study aims to provide engineers and designers with appropriate analysis tools and useful numerical results.

A literature review on the transverse linear vibration of tapered beams goes back to the work of Sanger [5], who analyzed free and forced flexural vibrations of tapered beams and gave general solutions, including the beam natural frequencies, in terms of Bessel functions of order $n$ for beams under various classical end conditions. Goel [6] investigated the transverse vibrations of a tapered beam elastically restrained by springs at its ends and a cantilever beam carrying a point mass at its free end. Using the straight search and bisection method, Craver et al. [7] investigated the free vibrations of tapered Euler-Bernoulli beams elastically 
restrained at an arbitrary position along their length. Abrate [8] presented simple formulas for determining the fundamental frequencies of a tapered beam under various end conditions based on the Rayleigh-Ritz approach. De Rosa [9] used the false position method to study a tapered beam whose width and depth vary according to a linear law and restrained elastically by rotational and translational springs at both ends. Laura et al. [10] investigated the free vibrations of bilinearly varying thickness beams using a finite element algorithmic procedure. Auciello [11] used the Rayleigh-Ritz method and a second approach to reduce the structure to a set of rigid elements to investigate the dynamic behaviour of two nonuniform beams subjected to axial loads. Banerjee et al. [12] studied the free vibration of rotating tapered beams by the dynamic stiffness method. Investigating linear free vibrations of a nonuniform beam with exponentially varying width, Mehmet et al. [13] presented a root equation in terms of natural frequency obtained from the end conditions and then solved it using Newton's method. Huang and Fang [14] presented a simple approach based on Fredholm integral equations, which facilitated the determination of the natural frequencies of tapered beams with variable flexural rigidity, mass density, and under various end conditions. Taha and Essam [15] investigated the stability and the free vibrations of axially loaded tapered columns with elastic end restraints using the differential quadrature method. Using the differential quadrature element method, Torabiet et al. [16] analyzed the free vibration of a Timoshenko tapered cantilever beam carrying multiple point masses. Abdelghany et al. [17] employed the differential transformation method to analyze the vibrations of a tapered circular Euler-Bernoulli beam. Using the perturbation method, Sohani and Eipakchi [18] performed a study on the flexural vibrations of nonuniform Euler Bernoulli and Timoshenko beams.

In contrast to the several publications on the free vibration of tapered beams, only a few papers are available that investigate the effect of geometrical nonlinearity. Raju et al. [19] investigated the nonlinear behaviour of two types of Euler Bernoulli tapered beams with either a linearly varying width or depth by Galerkin's method. The same beams have been investigated in [20] by Kanaka et al., who adopted Timoshenko beams theory and used the differential quadrature method. Kumar et al. [21] studied the large free vibrations amplitudes of axially functionally graded tapered beams with various taper profiles, material properties, and end conditions. The static case was solved using the principle of minimum total potential energy, while the dynamic case was examined using Hamilton's principle. None of the works mentioned above dealt with the geometrically nonlinear forced vibrations. The present work, dedicated to the study of the nonlinear dynamic behaviour of nonuniform tapered beams, presents further progress of the work initiated in [1] concerned with nonuniform beams of the stepped type.

Moreover, this work presents an extension of the studies previously initiated by Benamar et al. [3, 22], who studied the geometrical nonlinearity effects on different straight thin structures including beams, plates, and shells. Azrar et al. [23] used the single mode approach to examine free and forced vibrations of Euler-Bernoulli beams. Using a multimode approach, Azrar et al. [24] studied the geometrically nonlinear free and forced vibrations of uniform beams. In order to make it easy to use the model and solve the resulting nonlinear algebraic system, Kadiri et al. exposed simplified procedures and explored their applications to the geometrically nonlinear free and forced vibrations of clamped and simply supported beams in [25] and to rectangular plates in [26]. Rougui et al. [27] analyzed the geometrically nonlinear free and forced vibration of simply supported circular cylindrical shells using the single mode approach. Using the multimode and single-mode approaches, Merimi et al. [28] studied the case of a cracked beam excited by a harmonic concentrated force. Eddanguir et al. [29] used the so-called first formulation to investigate the geometrically nonlinear transverse forced vibration of multidegree-of-freedom systems. Boutahar et al. [30] used the iterative method of solution to investigate the nonlinear free vibration of functionally graded annular plates resting on elastic foundations. Khnaijar and Benamar [31] exposed a new discrete model to analyze the cracked beam case. Using an iterative method, Abdelali et al. [32] presented a study on the nonlinear bending and membrane stresses associated with the fundamental nonlinear mode shape of fully clamped skew plates. Fakhreddine et al. [33] used the multimode approach to investigate nonlinear forced vibrations of restrained beams resting on elastic point supports.

Linear beam solutions have been derived from the expressions for the transverse displacement, the bending rotation, the bending moment, and the shear force. These parameters are expressed in terms of Bessel functions of order $n$. To determine the natural frequencies, the boundary and compatibility conditions are expressed and developed. After calculating the frequencies through the NewtonRaphson algorithm, determination of the mode shapes is carried out. Once the linear problem is solved, the nonlinear problem is tackled by expanding the displacement functions as a series of the linear modes resulting from linear analysis and deriving the discrete expressions for the strain and kinetic energies. Then, the nonlinear algebraic system obtained using Hamilton's principle is solved by the multimode approach. The comparisons conducted in the linear and nonlinear cases established the validity and accuracy of the numerical method exposed. The effect of taper and section ratio on the free vibration behaviour was investigated and then illustrated. Forced vibrations have been studied for beams subjected to point excitations. Finally, the effect of the taper and section ratio on the nonlinear behaviour of forced tapered beams was also investigated and then illustrated.

\section{General Formulation}

2.1. Linear Formulation. The present study deals with the geometrically nonlinear transverse vibrations of a homogeneous nonuniform Euler-Bernoulli beam divided into two parts, as shown in Figure 1. Figure 2 presents two beams to be studied: (a) the first beam is tapered and has a thin rectangular cross section of constant width and a linearly varying depth, (b) the second beam is a double tapered beam 


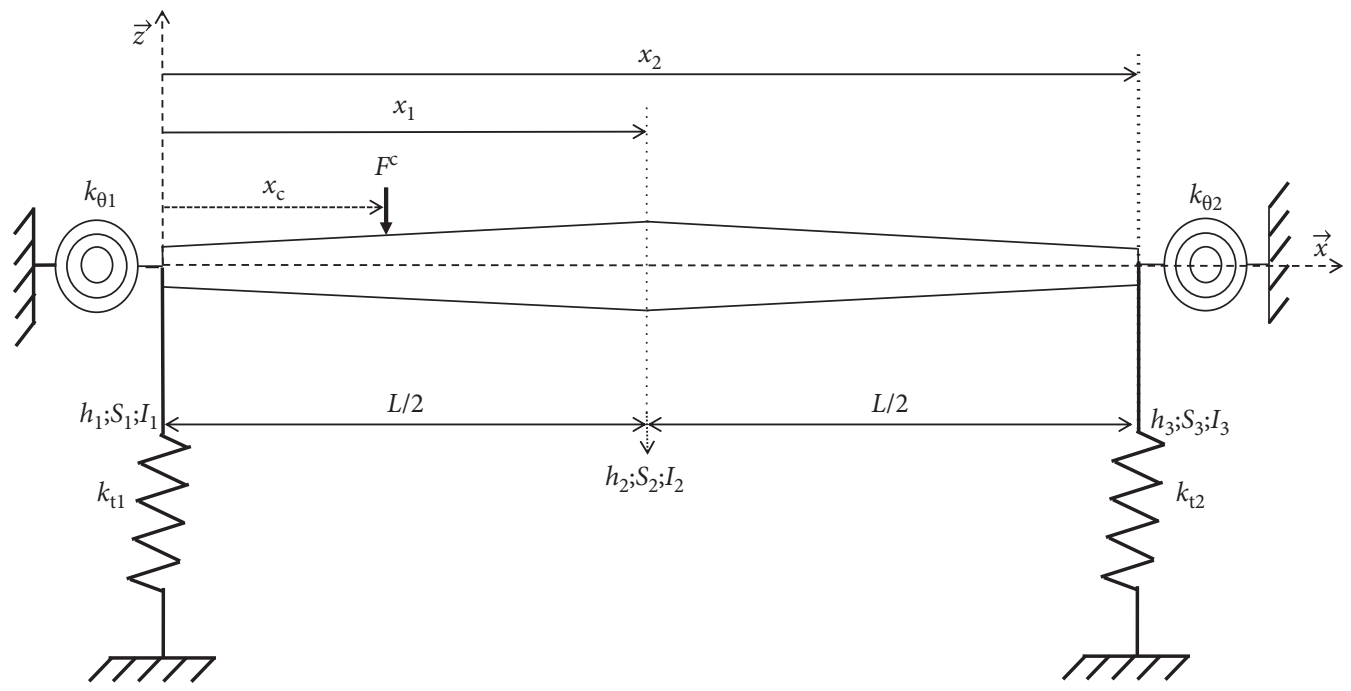

FIgURE 1: Coordinates system for a tapered beam with two steps.

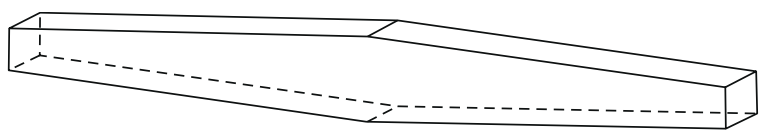

(a)

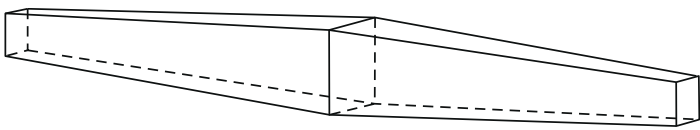

(b)

Figure 2: Two representative configurations of tapered beams. (a) Beam (a). (b) Beam (b).

with linearly varying width and depth. Both beams are supposed in what follows to be subjected to large transverse vibration amplitudes.

The equation of motion of a tapered beam undergoing free transverse vibrations can be written in the following usual form:

$$
\begin{aligned}
& \frac{\partial^{2}}{\partial x^{2}}\left\{E_{j} I_{j}(x) \frac{\partial^{2} w_{j}}{\partial x^{2}}\right\}+\rho_{j} S_{j}(x) \frac{\partial^{2} w_{j}}{\partial t^{2}}=0, \\
& x_{j} \varepsilon\left[0 L_{j}\right] ;(\text { For } j=1,2) .
\end{aligned}
$$

Each step of the tapered beams has a specified length, a cross section area, a moment of inertia, and eigenvalue parameters $\left(L_{j}, S_{j}, I_{j}\right.$ and $\left.\beta_{i j}\right)$. The cross section area of each step varies linearly, as illustrated in Figures 1 and 2. The cross section area $S(x)$ and the inertia $I(x)$ are expressed as follows:

$$
\begin{aligned}
& S(x)=\left\{\begin{array}{l}
S_{1}(x)=S_{1}\left(1+\frac{\alpha_{1} x}{L}\right)^{n} \Rightarrow\left[0, \frac{L}{2}\right] \\
S_{2}(x)=S_{2}\left(1-\frac{\alpha_{2} x}{L}\right)^{n} \Rightarrow\left[\frac{L}{2}, L\right]
\end{array}\right\}, \\
& I(x)=\left\{\begin{array}{l}
I_{1}(x)=I_{1}\left(1+\frac{\alpha_{1} x}{L}\right)^{n+2} \Rightarrow\left[0, \frac{L}{2}\right] \\
I_{2}(x)=I_{2}\left(1-\frac{\alpha_{2} x}{L}\right)^{n+2} \Rightarrow\left[\frac{L}{2}, L\right]
\end{array}\right\},
\end{aligned}
$$

where $\alpha_{1}$ and $\alpha_{2}$ present the first and second steps taper ratios, respectively. For a thin rectangular cross-section tapered beam of constant width and a linearly varying depth, the value of " $n$ " is 1 , while if both width and depth vary linearly, which corresponds to a double tapered beam, the value of " $n$ " is 2 . The variation at each step is presented by the ratios of taper, the cross-section areas, the moments of inertia, the length, and the eigenvalue parameters $\left(\alpha_{j}\right.$, $u_{j}, v_{j}, R_{j}$ and $z_{j}$ ).

$$
\begin{aligned}
& x_{j}^{*}=\frac{x_{j}}{L} ; \\
& R_{j}^{*}=\frac{L_{j}}{L} ; \\
& \alpha_{j}=2 \frac{\left|h_{j+1}-h_{j}\right|}{h_{j}}, \\
& z_{i j}=\frac{\beta_{i j}}{\beta_{i 1}} \\
& u_{j}=\frac{S_{j}}{S_{2}} ; \\
& v_{j}=\frac{I_{j}}{I_{2}}
\end{aligned}
$$

Substituting in equation (1), the expressions $S_{j}(x)=S_{j}\left(\xi_{j}\right)^{n}$ and $I_{j}(x)=I_{j}\left(\xi_{j}\right)^{n+2}$ leads to the formulation reported in [34]: 


$$
\xi_{j}^{2} \frac{d^{4} w_{i j}}{d \xi_{j}^{4}}+2(n+2) \xi_{j} \frac{d^{3} w_{i j}}{d \xi_{j}^{3}}+(n+2)(n+1) \frac{d^{2} w_{i j}}{d \xi_{j}^{2}}-\frac{\beta_{i j}^{4}}{\alpha_{j}} w_{i j}=0 ;(\text { For } i=1,2 \ldots, 10)
$$

where

$$
\beta_{i j}=\sqrt[4]{\frac{\rho \omega_{i j}^{2} L^{4} S_{j}}{E I_{j}}} .
$$

The eigenvalue parameter is denoted by $\beta_{i j}$. The solution of equation (1) gives the linear mode shapes, utilized as basic functions in the nonlinear theory explained below in detail.
The transverse displacement function of the tapered beams (a) and (b) can be written at each step as follows:

$$
w_{i}\left(x^{*}\right)=\left\{\begin{array}{l}
w_{i 1}\left(x^{*}\right) \longrightarrow\left[0, x_{1}^{*}\right] \\
w_{i 2}\left(x^{*}\right) \longrightarrow\left[x_{1}^{*}, 1\right]
\end{array}\right\}
$$

where $x_{j-1}^{*} \leq x^{*} \leq x_{j}^{*}$. This transverse displacement can also be expressed as in [34]:

$$
w_{i j}\left(\phi_{i j}\right)=\frac{1}{\left(\phi_{i j}\right)^{n}}\left(A_{j} J_{n}\left(\phi_{i j}\right)+B_{j} Y_{n}\left(\phi_{i j}\right)+C_{j} I_{n}\left(\phi_{i j}\right)+D_{j} K_{n}\left(\phi_{i j}\right)\right),
$$

with

$$
\phi_{i j}=\left(\frac{2 \beta_{i j}}{\alpha_{j}}\right) \sqrt{\xi_{j}}
$$

The constants $A_{j}, B_{j}, C_{j}$, and $D_{j}$ of equation (7) are determined from the end and compatibility conditions. The first and second type Bessel functions of order $n$ are denoted by $J_{n}$ and $Y_{n}$ while $I_{n}$ and $K_{n}$ are the modified Bessel functions of first and second kinds of order " $n$." They have a $\phi$ argument. Hence, they are dependent on $\xi$. Furthermore, the expressions for the bending rotation $Y_{i j}(x)$, the bending moment $M_{i j}(x)$, and the shear force $P_{i j}(x)$ at each step can be derived after a few mathematical operations on the Bessel functions. Setting that

$$
\begin{aligned}
Y_{i j}(x) & =\frac{\mathrm{d} w_{i j}}{\mathrm{~d} x}, \\
M_{i j}(x) & =-E I_{j}(x) \frac{\mathrm{d}^{2} w_{i j}}{\mathrm{~d} x^{2}}, \\
P_{i j}(x) & =\frac{\mathrm{d}}{\mathrm{d} x}\left(E I_{j}(x) \frac{\mathrm{d}^{2} w_{i j}}{\mathrm{~d} x^{2}}\right) .
\end{aligned}
$$

Equations (9)-(11) can be written in the following form:

$$
\begin{aligned}
& Y_{i j}(x)=-\frac{\beta_{i j}}{L \sqrt{\xi_{j}}\left(\phi_{i j}\right)^{n}}(-1)^{j-1}\left[A_{j} J_{n+1}\left(\phi_{i j}\right)+B_{j} Y_{n+1}\left(\phi_{i j}\right)-C_{j} I_{n+1}\left(\phi_{i j}\right)+D_{j} K_{n+1}\left(\phi_{i j}\right)\right], \\
& M_{i j}(x)=\frac{-E I_{j}\left(\xi_{j}\right)^{n+1}\left(\beta_{i j}\right)^{2}}{L^{2} \phi^{n}}\left[A_{j} J_{n+2}\left(\phi_{i j}\right)+B_{j} Y_{n+2}\left(\phi_{i j}\right)+C_{j} I_{n+2}\left(\phi_{i j}\right)+D_{j} K_{n+2}\left(\phi_{i j}\right)\right], \\
& P_{i j}(x)=(-1)^{j-1} \frac{E I_{j}\left(\beta_{i j}\right)^{3} \phi^{-n}}{L^{3}\left(\xi_{j}\right)^{-(n+1 / 2)}}\left[A_{j} J_{n+1}\left(\phi_{i j}\right)+B_{j} Y_{n+1}\left(\phi_{i j}\right)+C_{j} I_{n+1}\left(\phi_{i j}\right)-D_{j} K_{n+1}\left(\phi_{i j}\right)\right] .
\end{aligned}
$$

2.1.1. The End Conditions. The support conditions are modeled by two types of springs, translational and rotational, retaining the beam on both ends. They are expressed as in [35]:

At the left end,

$$
\begin{aligned}
\left.P_{i 1}\left(x^{*}\right)\right|_{x^{*}=0}+\left.k_{t 1} w_{i 1}\left(x^{*}\right)\right|_{x^{*}=0} & =0, \\
\left.M_{i 1}\left(x^{*}\right)\right|_{x^{*}=0}+\left.k_{\theta 1} Y_{i 1}\left(x^{*}\right)\right|_{x^{*}=0} & =0 .
\end{aligned}
$$

At the right end,

$$
\begin{array}{r}
\left.P_{i 2}\left(x^{*}\right)\right|_{x^{*}=1}-\left.k_{t 2} w_{i 2}\left(x^{*}\right)\right|_{x^{*}=1}=0, \\
\left.M_{i 2}\left(x^{*}\right)\right|_{x^{*}=1}-\left.k_{\theta 2} Y_{i 2}\left(x^{*}\right)\right|_{x^{*}=1}=0 .
\end{array}
$$

The stiffness values of the transverse and rotary springs at both ends of the beam are denoted by $\left(k_{t 1}, k_{t 2}, k_{\theta 1}, k_{\theta 2}\right)$. After some algebra, these boundary conditions can be written as follows: 


$$
\begin{aligned}
& \left(\frac{E I_{j}\left(\beta_{i 1}\right)^{3}}{\left(\phi_{0}\right)^{n}}\right)\left[A_{1} J_{n+1}\left(\phi_{0}\right)+B_{1} Y_{n+1}\left(\phi_{0}\right)+C_{1} I_{n+1}\left(\phi_{0}\right)-D_{1} K_{n+1}\left(\phi_{0}\right)\right] \\
& +\frac{k_{t 1}}{\left(\phi_{0}\right)^{n}}\left(A_{1} J_{n}\left(\phi_{0}\right)+B_{1} Y_{n}\left(\phi_{0}\right)+C_{1} I_{n}\left(\phi_{0}\right)+D_{1} K_{n}\left(\phi_{0}\right)\right) \\
& A_{1}\left[d_{11}\right]+B_{1}\left[d_{12}\right]+C_{1}\left[d_{13}\right]-D_{1}\left[d_{14}\right]=0, \\
& \left(\frac{-E I_{1}\left(\beta_{i 1}\right)^{2}}{\left(\phi_{0}\right)^{n}}\right)\left[A_{1} J_{n+2}\left(\phi_{0}\right)+B_{1} Y_{n+2}\left(\phi_{0}\right)+C_{1} I_{n+2}\left(\phi_{0}\right)+D_{1} K_{n+2}\left(\phi_{0}\right)\right] \\
& +k_{\theta 1}\left(\frac{-\beta_{i j}}{\left(\phi_{0}\right)^{n}}\right)\left[A_{1} J_{n+1}\left(\phi_{0}\right)+B_{1} Y_{n+1}\left(\phi_{0}\right)-C_{1} I_{n+1}\left(\phi_{0}\right)+D_{1} K_{n+1}\left(\phi_{0}\right)\right]=0, \\
& A_{1}\left[d_{21}\right]+B_{1}\left[d_{22}\right]+C_{1}\left[d_{22}\right]+D_{1}\left[d_{24}\right]=0, \\
& \left(-\frac{E I_{2}\left(\beta_{i 2}\right)^{3}}{\left(\psi_{1}\right)^{n}}\right)\left[A_{2} J_{n+1}\left(\psi_{1}\right)+B_{2} Y_{n+1}\left(\psi_{1}\right)+C_{2} I_{n+1}\left(\psi_{1}\right)-D_{2} K_{n+1}\left(\psi_{1}\right)\right] \\
& -\frac{k_{t 2}}{\left(\psi_{1}\right)^{n}}\left(A_{2} J_{n}\left(\psi_{1}\right)+B_{2} Y_{n}\left(\psi_{1}\right)+C_{2} I_{n}\left(\psi_{1}\right)+D_{2} K_{n}\left(\psi_{1}\right)\right)=0, \\
& A_{2}\left[d_{31}\right]+B_{2}\left[d_{32}\right]+C_{2}\left[d_{33}\right]-D_{2}\left[d_{34}\right]=0, \\
& \left(\frac{-E I_{2}\left(\beta_{i 2}\right)^{2}}{\left(\psi_{1}\right)^{n}}\right)\left[A_{2} J_{n+2}\left(\psi_{1}\right)+B_{2} Y_{n+2}\left(\psi_{1}\right)+C_{2} I_{n+2}\left(\psi_{1}\right)+D_{2} K_{n+2}\left(\psi_{1}\right)\right] \\
& -\left(\frac{k_{\theta 2} \beta_{i 2}}{\left(\psi_{1}\right)^{n}}\right)\left[A_{2} J_{n+1}\left(\psi_{1}\right)+B_{2} Y_{n+1}\left(\psi_{1}\right)-C_{2} I_{n+1}\left(\psi_{1}\right)+D_{2} K_{n+1}\left(\psi_{1}\right)\right]=0, \\
& A_{2}\left[d_{41}\right]+B_{2}\left[d_{42}\right]+C_{2}\left[d_{43}\right]+D_{2}\left[d_{44}\right]=0 .
\end{aligned}
$$

where

$$
\begin{aligned}
& \phi_{0}= \frac{2 \beta_{i 1}}{\alpha_{1}}, \\
& K_{t 1}= \frac{k_{t 1}}{E I_{1}}, \\
& K_{\theta 1}= \frac{k_{\theta 1}}{E I_{1}}, \\
& \cdot \begin{array}{l}
d_{11}=J_{n+1}\left(\phi_{0}\right)+\frac{K_{t 1}}{\left(\beta_{i 1}\right)^{3}} J_{n}\left(\phi_{0}\right) \\
d_{12}=Y_{n+1}\left(\phi_{0}\right)+\frac{K_{t 1}}{\left(\beta_{i 1}\right)^{3}} Y_{n}\left(\phi_{0}\right) \\
d_{13}=I_{n+1}\left(\phi_{0}\right)+\frac{K_{t 1}}{\left(\beta_{i 1}\right)^{3}} I_{n}\left(\phi_{0}\right)
\end{array}, \\
& d_{14}=K_{n+1}\left(\phi_{0}\right)-\frac{K_{t 1}}{\left(\beta_{i 1}\right)^{3}} K_{n}\left(\phi_{0}\right)
\end{aligned}
$$

$$
\mid \begin{aligned}
d_{21} & =J_{n+2}\left(\phi_{0}\right)+\frac{K_{\theta 1}}{\beta_{i 1}} J_{n+1}\left(\phi_{0}\right) \\
d_{22} & =Y_{n+2}\left(\phi_{0}\right)+\frac{K_{\theta 1}}{\beta_{i 1}} Y_{n+1}\left(\phi_{0}\right) \\
d_{23} & =I_{n+2}\left(\phi_{0}\right)-\frac{K_{\theta 1}}{\beta_{i 1}} I_{n+1}\left(\phi_{0}\right) \\
d_{24} & =K_{n+2}\left(\phi_{0}\right)+\frac{K_{\theta 1}}{\beta_{i 1}} K_{n+1}\left(\phi_{0}\right) \\
\psi_{1} & =\left(\frac{2 \beta_{i 2}}{\alpha_{2}} \sqrt{1-\alpha_{2}}\right) \\
K_{t 2} & =\frac{k_{t 2}}{E I_{2}}, \\
K_{\theta 2} & =\frac{k_{\theta 2}}{E I_{2}}, \\
d_{31} & =J_{n+1}\left(\psi_{1}\right)+\frac{K_{t 2}}{\left(\beta_{i 2}\right)^{3}} J_{n}\left(\psi_{1}\right) \\
d_{32} & =Y_{n+1}\left(\psi_{1}\right)+\frac{K_{t 2}}{\left(\beta_{i 2}\right)^{3}} Y_{n}\left(\psi_{1}\right) \\
d_{33} & =I_{n+1}\left(\psi_{1}\right)+\frac{K_{t 2}}{\left(\beta_{i 2}\right)^{3}} I_{n}\left(\psi_{1}\right) \\
d_{34} & =K_{n+1}\left(\psi_{1}\right)-\frac{K_{t 2}}{\left(\beta_{i 2}\right)^{3}} K_{n}\left(\psi_{1}\right)
\end{aligned}
$$




$$
\left\{\begin{array}{l}
d_{41}=J_{n+2}\left(\psi_{1}\right)+\frac{K_{\theta 2}}{\beta_{i 2}} J_{n+1}\left(\psi_{1}\right) \\
d_{42}=Y_{n+2}\left(\psi_{1}\right)+\frac{K_{\theta 2}}{\beta_{i 2}} Y_{n+1}\left(\psi_{1}\right) \\
d_{43}=I_{n+2}\left(\psi_{1}\right)-\frac{K_{\theta 2}}{\beta_{i 2}} I_{n+1}\left(\psi_{1}\right) \\
d_{44}=K_{n+2}\left(\psi_{1}\right)+\frac{K_{\theta 2}}{\beta_{i 2}} K_{n+1}\left(\psi_{1}\right)
\end{array}\right.
$$

2.1.2. The Compatibility Conditions. The compatibility conditions at each step of the tapered beam considered are expressed as in [35]. By neglecting the mass magnitude and the rotational inertia, these conditions can be given as follows:

$$
\begin{gathered}
\left.w_{i j}\left(x^{*}\right)\right|_{x^{*}=x_{j}^{*}}=\left.w_{i j+1}\left(x^{*}\right)\right|_{x^{*}=x_{j}^{*}}, \\
\left.Y_{i j}\left(x^{*}\right)\right|_{x^{*}=x_{j}^{*}}=\left.Y_{i j+1}\left(x^{*}\right)\right|_{x^{*}=x_{j}^{*}}, \\
\left.M_{i j}\left(x^{*}\right)\right|_{x^{*}=x_{j}^{*}}=\left.M_{i j+1}\left(x^{*}\right)\right|_{x^{*}=x_{j}^{*}}, \\
\left.P_{i j}\left(x^{*}\right)\right|_{x^{*}=x_{j}^{*}}=\left.P_{i j+1}\left(x^{*}\right)\right|_{x^{*}=x_{j}^{*}} .
\end{gathered}
$$

After calculations, these compatibility conditions can be written as follows:

$$
\begin{aligned}
& \quad\left(A_{1} J_{n}\left(\phi_{1}\right)+B_{1} Y_{n}\left(\phi_{1}\right)+C_{1} I_{n}\left(\phi_{1}\right)+D_{1} K_{n}\left(\phi_{1}\right)\right)+\lambda_{1}\left(A_{2} J_{n}\left(\psi_{0}\right)\right. \\
& \left.\quad+B_{2} Y_{n}\left(\psi_{0}\right)+C_{2} I_{n}\left(\psi_{0}\right)+D_{2} K_{n}\left(\psi_{0}\right)\right)=0, \\
& {\left[A_{1} J_{n+1}\left(\phi_{1}\right)+B_{1} Y_{n+1}\left(\phi_{1}\right)-C_{1} I_{n+1}\left(\phi_{1}\right)+D_{1} K_{n+1}\left(\phi_{1}\right)\right]} \\
& \quad+\lambda_{i 2}\left[A_{2} J_{n+1}\left(\psi_{0}\right)+B_{2} Y_{n+1}\left(\psi_{0}\right)-C_{2} I_{n+1}\left(\psi_{0}\right)+D_{2} K_{n+1}\left(\psi_{0}\right)\right]=0, \\
& \quad\left[A_{1} J_{n+2}\left(\phi_{1}\right)+B_{1} Y_{n+2}\left(\phi_{1}\right)+C_{1} I_{n+2}\left(\phi_{1}\right)+D_{1} K_{n+2}\left(\phi_{1}\right)\right] \\
& \quad+\lambda_{i 3}\left[A_{2} J_{n+2}\left(\psi_{0}\right)+B_{2} Y_{n+2}\left(\psi_{0}\right)+C_{2} I_{n+2}\left(\psi_{0}\right)+D_{2} K_{n+2}\left(\psi_{0}\right)\right]=0, \\
& {\left[A_{1} J_{n+1}\left(\phi_{1}\right)+B_{1} Y_{n+1}\left(\phi_{1}\right)+C_{1} I_{n+1}\left(\phi_{1}\right)-D_{1} K_{n+1}\left(\phi_{1}\right)\right]} \\
& \quad+\lambda_{i 4}\left[A_{2} J_{n+1}\left(\psi_{0}\right)+B_{2} Y_{n+1}\left(\psi_{0}\right)+C_{2} I_{n+1}\left(\psi_{0}\right)-D_{2} K_{n+1}\left(\psi_{0}\right)\right]=0,
\end{aligned}
$$

where

$$
\begin{aligned}
& \psi_{0}=\left(\frac{2 \beta_{i 2}}{\alpha_{2}}\right), \\
& \phi_{1}=\left(\frac{2 \beta_{i 1}}{\alpha_{1}} \sqrt{1+\alpha_{1}}\right), \\
& \lambda_{1}=-\left(\frac{\phi_{1}}{\psi_{0}}\right)^{n}, \\
& \lambda_{i 2}=\left(z_{i 2}\right)^{1-n}\left(\frac{\sqrt{\xi_{1}\left(x_{1}\right)}}{\sqrt{\xi_{2}\left(x_{1}\right)}}\right)^{n+1}\left(\frac{\alpha_{2}}{\alpha_{1}}\right)^{n}, \\
& \lambda_{i 3}=-\left(v_{1}\right)^{-1}\left(z_{i 2}\right)^{2}\left(\frac{\xi_{2}\left(x_{1}\right)}{\xi_{1}\left(x_{1}\right)}\right)^{n+1}\left(\frac{\phi_{1}}{\psi_{0}}\right)^{n}, \\
& \lambda_{i 4}=\left(v_{1}\right)^{-1}\left(z_{i 2}\right)^{3}\left(\frac{\phi_{1}}{\phi_{0}}\right)^{n}\left(\frac{\xi_{2}\left(x_{1}\right)}{\xi_{1}\left(x_{1}\right)}\right)^{n+1 / 2} .
\end{aligned}
$$


Equations (21) and (22) present the mathematical development derived, respectively, from equations (17) and (18), while equations (23) and (24) are derived from equations (19) and (20), respectively.

The satisfaction of the end conditions was achieved for the two types of tapered beam considered. Eight equations are obtained for each configuration, which is subsequently expressed in terms of $n$, presenting the index of the tapered beam type. By varying the indices $i$ from 1 to 10 and $j$ from 1 to 2 , the satisfaction of the end and the compatibility conditions leads to a homogeneous system, written in a matrix form for each configuration as follows:

$$
\begin{aligned}
& \left\{\eta_{i}\right\}=\left\{\begin{array}{c}
A_{i 1} \\
B_{i 1} \\
C_{i 1} \\
D_{i 1} \\
A_{i 2} \\
B_{i 2} \\
C_{i 2} \\
D_{i 2}
\end{array}\right\}, \\
& M_{n}=\left[\begin{array}{cccccccc}
d_{11} & d_{12} & d_{13} & d_{13} & 0 & 0 & 0 & 0 \\
d_{21} & d_{22} & d_{23} & d_{24} & 0 & 0 & 0 & 0 \\
J_{n}\left(\phi_{1}\right) & Y_{n}\left(\phi_{1}\right) & I_{n}\left(\phi_{1}\right) & K_{n}\left(\phi_{1}\right) & \lambda_{1} J_{n}\left(\psi_{0}\right) & \lambda_{1} Y_{n}\left(\psi_{0}\right) & \lambda_{1} I_{n}\left(\psi_{0}\right) & \lambda_{1} K_{n}\left(\psi_{0}\right) \\
J_{n+1}\left(\phi_{1}\right) & Y_{n+1}\left(\phi_{1}\right) & -I_{n+1}\left(\phi_{1}\right) & K_{n+1}\left(\phi_{1}\right) & \lambda_{i 2} J_{n+1}\left(\psi_{0}\right) & \lambda_{i 2} Y_{n+1}\left(\psi_{0}\right) & -\lambda_{i 2} I_{n+1}\left(\psi_{0}\right) & \lambda_{i 2} K_{n+1}\left(\psi_{0}\right) \\
J_{n+2}\left(\phi_{1}\right) & Y_{n+2}\left(\phi_{1}\right) & I_{n+2}\left(\phi_{1}\right) & K_{n+2}\left(\phi_{1}\right) & \lambda_{i 3} J_{n+2}\left(\psi_{0}\right) & \lambda_{i 3} Y_{n+2}\left(\psi_{0}\right) & \lambda_{i 3} I_{n+2}\left(\psi_{0}\right) & \lambda_{i 3} K_{n+2}\left(\psi_{0}\right) \\
J_{n+1}\left(\phi_{1}\right) & Y_{n+1}\left(\phi_{1}\right) & I_{n+1}\left(\phi_{1}\right) & -K_{n+1}\left(\phi_{1}\right) & \lambda_{i 4} J_{n+1}\left(\psi_{0}\right) & \lambda_{i 4} Y_{n+1}\left(\psi_{0}\right) & \lambda_{i 4} I_{n+1}\left(\psi_{0}\right) & -\lambda_{i 4} K_{n+1}\left(\psi_{0}\right) \\
0 & 0 & 0 & 0 & d_{31} & d_{32} & d_{33} & d_{34} \\
0 & 0 & 0 & 0 & d_{41} & d_{42} & d_{43} & d_{44}
\end{array}\right],
\end{aligned}
$$$$
\left[M_{n}\right] \times\left\{\eta_{i}\right\}=\{0\} .
$$

The case of a tapered beam supported by linear and rotational springs attached at both ends is presented by the homogeneous system (28), whose solution, obtained by setting the determinant of $M_{n}$ equal to zero in order to find the nontrivial solutions, determines the eigenvalues:

$$
\operatorname{det}\left(M_{n}\right)=\left|M_{n}\right|=0 .
$$

The nontrivial solutions corresponding to the natural frequencies are deduced from equation (27) and are subsequently calculated iteratively by the Newton-Raphson method. Then, the constants $A_{i 1}, B_{i 1}, C_{i 1}, D_{i 1}, A_{i 2}, B_{i 2}, C_{i 2}$ and $D_{i 2}$ are determined by classical algebra.

2.2. Nonlinear Formulation. The study of free and forced geometrically nonlinear vibrations is performed for both configurations, which differ in the type of cross section. The formulation given in this analysis presents the forced case but may also be used to investigate the free case if the force term is neglected. In order to determine the dynamics of the tapered beams, Hamilton's principle is applied and formally expressed as in [36]:

$$
\delta \int_{0}^{\frac{2 \omega}{t}}\left(V-T+W_{F}\right) \mathrm{d} t=0,
$$

where $T, V$, and $W_{\mathrm{F}}$ indicate, respectively, the kinetic energy, the total strain energy, and the work done by the external loads. The tapered beam's kinetic energy can be written as in [37]:

$$
T=\frac{\rho}{2} \int_{0}^{L} S(x)\left(\frac{\partial W}{\partial t}\right)^{2} \mathrm{~d} x .
$$

Equation (31) can be formulated as follows:

$$
T=\frac{\rho}{2}\left[\int_{0}^{x_{1}} S_{1}(x)\left(\frac{\partial W_{1}}{\partial t}\right)^{2} \mathrm{~d} x+\int_{x_{1}}^{L} S_{2}(x)\left(\frac{\partial W_{2}}{\partial t}\right)^{2} \mathrm{~d} x\right] .
$$

The tapered beam total strain energy can be expressed as the sum of two energies $V_{f}$ and $V_{a}$, referring, respectively, to the bending energy and to the energy due to the nonlinear stretching forces induced by large deflections.

$$
V=V_{f}+V_{a} .
$$

The energy $V_{f}$ can be written as in [20] by the following:

$$
V_{f}=\frac{1}{2} \int_{0}^{L} E I(x)\left(W_{2}^{\prime \prime}\right)^{2} \mathrm{~d} x .
$$


Equation (34) can be formulated as follows:

$V_{f}=\frac{E}{2}\left[\int_{0}^{x_{1}} I_{1}(x)\left(\frac{\mathrm{d}^{2} W_{1}}{\mathrm{~d} x^{2}}\right)^{2} \mathrm{~d} x+\int_{x_{1}}^{L} I_{2}(x)\left(\frac{\mathrm{d}^{2} W_{2}}{\mathrm{~d} x^{2}}\right)^{2} \mathrm{~d} x\right]$.

The energy $V_{a}$ can be written in the following form previously stated in [1]:

$$
V_{a}=\frac{1}{2} \int_{0}^{L} \varepsilon_{s} N_{x} \mathrm{~d} x,
$$

in which $N_{x}$, presenting the beam nonlinear stretching force, is expressed as in [19]:

$$
N_{x}=\frac{E}{2} \cdot \frac{\int_{0}^{L}(\mathrm{~d} W / \mathrm{d} x)^{2} \mathrm{~d} x}{\int_{0}^{L} \mathrm{~d} x / S}
$$

where

$$
\int_{0}^{L} \frac{\mathrm{d} x}{S(x)}=\frac{1}{S_{2}}\left[\int_{0}^{x_{1}} \frac{\mathrm{d} x}{u_{1}\left(\xi_{1}\right)^{n}}+\int_{x_{1}}^{L} \frac{\mathrm{d} x}{\left(\xi_{2}\right)^{n}}\right]=\frac{C}{S_{2}} .
$$

The nonlinear axial strain $\varepsilon_{s}$ is written as follows:

$$
\varepsilon_{s}=\frac{N_{x}}{E S} \text {. }
$$

Substituting equations (37a)-(37c) in equation (36) gives

$$
\begin{aligned}
V_{a} & =\frac{1}{2} \int_{0}^{L} \frac{N_{x}^{2}}{E S(x)} \mathrm{d} x, \\
V_{a} & =\left[\frac{E}{2} \cdot \frac{\int_{0}^{L}(\mathrm{~d} W / \mathrm{d} x)^{2} \mathrm{~d} x}{\int_{0}^{L} \mathrm{~d} x / S(x)}\right]^{2} \frac{1}{2 E} \int_{0}^{L} \frac{\mathrm{d} x}{S(x)}, \\
V_{a} & =\frac{E S_{2}}{8 L} \cdot \frac{\left(\int_{0}^{L}(\mathrm{~d} W / \mathrm{d} x)^{2} \mathrm{~d} x\right)^{2}}{C} .
\end{aligned}
$$

If a harmonic motion is assumed and the transverse displacement is expanded as a finite series of basic spatial functions, one can write the following:

$$
W(x, t)=a_{i} w_{i}(x) \sin (\omega t),
$$

where $w_{i}(x)$ and $a_{i}$ present, respectively, the tapered beam linear modes and their contribution coefficient. Referring to the new $W$ expression and substituting it into $(32,35$, and 38c), the following expressions are obtained for the kinetic energy, the axial strain energy and the strain energy as reported in [38]:

$$
\begin{aligned}
T & =\frac{1}{2} \omega^{2} a_{i} a_{i}(\cos (\omega t))^{2} m_{i j}, \\
V_{a} & =\frac{1}{2} a_{i} a_{j} a_{k} a_{l}(\sin (\omega t))^{4} b_{i j k l}, \\
V_{f} & =\frac{1}{2} a_{i} a_{i}(\sin (\omega t))^{2} k_{i j} .
\end{aligned}
$$

The matrices $m_{i j}$ present, respectively, the mass matrix, the rigidity matrix, and the nonlinearity tensor, expressed by the following:

$$
\begin{aligned}
m_{i j}= & \frac{\rho S_{2}}{2}\left[\int_{0}^{x_{1}} u_{1}\left(\xi_{1}\right)^{n} w_{i 1} w_{j 1} \mathrm{~d} x+\int_{x_{1}}^{L} u_{2}\left(\xi_{2}\right)^{n} w_{i 2} w_{j 2} \mathrm{~d} x\right], \\
k_{i j}= & \frac{E I_{2}}{2}\left[\int_{0}^{x_{1}} v_{1}\left(\xi_{1}\right)^{n+2}\left(\frac{d^{2} w_{i 1}}{\mathrm{~d} x^{2}} \frac{d^{2} w_{j 1}}{\mathrm{~d} x^{2}}\right) \mathrm{d} x\right. \\
& \left.+\int_{x_{1}}^{L} v_{2}\left(\xi_{2}\right)^{n+2}\left(\frac{d^{2} w_{i 2}}{\mathrm{~d} x^{2}} \frac{d^{2} w_{j 2}}{\mathrm{~d} x^{2}}\right) \mathrm{d} x\right] \\
b_{i j k l}= & \frac{E S_{2}}{4 . C}\left[\int_{0}^{L} \frac{\mathrm{d} w_{i}}{\mathrm{~d} x} \frac{\mathrm{d} w_{j}}{\mathrm{~d} x} \mathrm{~d} x\right]\left[\int_{0}^{L} \frac{\mathrm{d} w_{k}}{\mathrm{~d} x} \frac{\mathrm{d} w_{l}}{\mathrm{~d} x} \mathrm{~d} x\right] .
\end{aligned}
$$
[24]:

The work done by the external loads is expressed as in

$$
W_{F}=\int_{S} F(x, t) w_{i}(x) \mathrm{d} x .
$$

The work done by the external loads excites the modes of the structures via a set of generalized forces denoted by $F_{i}^{c}$ and expressed by the following [28]:

$$
F_{i}^{c}=F^{c} w_{i}\left(x_{c}\right) \sin (\omega t)=f_{i}^{c} \sin (\omega t),
$$

with $x_{c}$ being the position of the point force $F^{c}$. Using equations (41)-(45) and applying Hamilton's principle leads to the following:

$$
2 a_{i} k_{i r}+3 a_{i} a_{j} a_{k} b_{i j k r}-2 \omega_{n l}^{2} a_{i} m_{i r}=f_{i}^{c} ; r=1, \ldots, n
$$

As in [25], the above equation can be expressed in a matrix form as follows:

$$
2[K]\{A\}+3[B(\{A\})]\{A\}-2 \omega_{n l}^{2}[M]\{A\}=\{F\},
$$

where the column vector of contribution coefficients $\{A\}$ and the nonlinear frequency $\left(\omega_{n l}\right)$ are the unknowns to be determined from equation (47) after writing it in a dimensionless form by replacing the dimensional parameters by appropriate nondimensional parameters as follows: 


$$
\begin{aligned}
\frac{w_{i}\left(x^{*}\right)}{w_{i}^{*}\left(x^{*}\right)} & =h_{2}, \\
\frac{\omega^{2}}{\omega^{* 2}} & =\frac{E I_{2}}{\rho S_{2} L^{4}}, \\
\frac{M_{i j}}{M_{i j}^{*}} & =\rho S_{2} h_{2}^{2} L, \\
K_{i j} & =\frac{E I_{2} h_{2}^{2}}{L^{3}} K_{i j}^{*}, \\
B_{i j k l} & =\frac{E I_{2} h_{2}^{2}}{L^{3}} B_{i j k l}^{*}, \\
F^{c} & =\frac{E I_{2} h_{2}}{L^{3}} f_{i}^{c *},
\end{aligned}
$$

which leads to the following:

$$
\left(\left[K^{*}\right]-\omega_{n l}^{* 2}\left[M^{*}\right]\right)\{A\}+\frac{3}{2}\left[B^{*}(\{A\})\right]\{A\}=\left\{F^{*}\right\} .
$$

The unknowns are determined using the second formulation developed in [25], based on the fact that the first mode contribution coefficient $a_{1}$ remains predominant, compared to the other coefficients denoted as $\varepsilon_{j}, j=2$ to $N$, for the whole vibration amplitudes range of interest. This allows one after neglecting higher-order terms to write: $a_{i} a_{j} a_{k} b_{i j k r}^{*}=a_{1}^{3} b_{111 r}+a_{1}^{2} \varepsilon_{i} b_{11 i r}$ which gives the following after substitution into equation (49), as mentioned in [25]:

$$
\begin{aligned}
& \left(\left[K_{r}^{*}\right]_{R}-\omega_{n l}^{* 2}\left[M_{r}^{*}\right]_{R}\right)\left\{A_{r}\right\}_{R}+\frac{3}{2}\left[\alpha_{r}^{*}\right]\left\{A_{r}\right\}_{R}=\left\{F^{*}-\frac{3}{2} a_{r}^{3} b_{i r r}^{*}\right\}, \text { for } \\
& \left\{A_{r}\right\}=\left\{a_{1}, \varepsilon_{2}, \ldots, \varepsilon_{N}\right\},
\end{aligned}
$$

where

$$
\left[\alpha_{r}^{*}\right]=a_{r}^{2} b_{i j r r}^{*} \text { for } r=1, \ldots, N .
$$

The calculation of $\left\{A_{r}\right\}$ is greatly facilitated by adopting this approach which may be applied to nonlinear forced vibrations by assigning to $F^{c}$ a given value and to the free case by replacing it by zero. After calculating the contribution coefficients and the associated nonlinear frequencies, the normalized first nonlinear mode $W_{\mathrm{nl}}^{*}\left(x, a_{1}\right)$ can be obtained, for each given value of $a_{1}$, as a series of bilinear combinations of the beam linear modes $w_{1}^{*}, \ldots, w_{N}^{*}$ :

$$
W_{n l}^{*}\left(x, a_{1}\right)=a_{1} w_{1}^{*}+\varepsilon_{2} w_{2}^{*}+\varepsilon_{3} w_{3}^{*}+\cdots+\varepsilon_{N} w_{N}^{*} .
$$

In the above series, the predominant term $a_{1} w_{1}^{*}$ is proportional to the first linear mode shape, while the remaining terms $\varepsilon_{2} w_{2}^{*}, \varepsilon_{3} w_{3}^{*} \ldots, \varepsilon_{N} w_{N}^{*}$ present the correction due to the geometrical nonlinearity. Although the correction remains small compared to $a_{1} w_{1}^{*}$ in terms of displacement magnitudes, it may induce significant changes in the corresponding strains and stresses, as shown below.

\section{Numerical Results and Discussion}

The formulation and procedure of the solution mentioned above have been used to examine nonlinear free and forced vibrations of the two tapered beams (a) and (b) mentioned above and shown in Figure 2 via a Matlab program developed to this end. The validity of the results obtained by the present approach in the linear case has been first established by comparisons with those previously obtained in [34], summarized in Tables 1-4. A second comparison was made in the nonlinear case with results reported in $[19,20]$.

The present linear results are compared in Tables 1-4 with those of [34], showing an excellent agreement since the relative difference does not exceed $0.008 \%$ for simply supported beams and $0.05 \%$ for clamped beams. In the nonlinear case, the comparisons performed, and summarized in Table 5, between the results obtained here by the second formulation and those of $[19,20]$, correspond to tapered beams clamped at both ends and denoted by (C-C) and to beams simply supported at both ends and denoted by (SS-SS).

The results obtained show an excellent agreement, as the relative differences do not exceed $1.9 \%$ and $1.23 \%$, respectively, for nondimensional vibration amplitudes up to 3 .

For the rest of this study, the beams studied in the nonlinear case are clamped at both ends. Consequently, an infinite value is assigned to the stiffness of the linear and rotational springs $\left(k_{t 1}, k_{t 2}, k_{\theta 1}\right.$ and $\left.k_{\theta 2}\right)$.

Before starting the parametric study, the size of the beams investigated is first parametrized by geometrical parameters which remain constant for all the scenarios such as the length ratios $R_{1}^{*}=R_{2}^{*}=0.5$, the seconds depth, and moment of inertia, whose, respectively, equal to $h_{2}=1$ and $I_{2}=1 / 12$. Secondly, a symmetric shape conditions are performed as follows: $\left[h_{1}=h_{3}\right.$ and $h_{1}<h_{2}$ ]; $S_{1}=S_{3}$ and $S_{1}<S_{2}$ ]. Finally, the parametric study was carried out by varying the taper ratio parameter $e$ for beam (a) and (b), after setting that $\alpha_{2}=2 e$, and then varying the section ratio $u_{1}$ for beam (b). The size of the beams obtained after each variation of $e$ and $u_{1}$, is defined by the ratios summarized in Tables 6 and 7 .

3.1. Nonlinear Free Vibration. The effect of geometrically nonlinear vibrations of the two beams shown in Figure 2 is investigated in terms of the variation of taper, section, and inertia ratios. The effect of the taper ratio can be seen in the backbone curves associated with the first nonlinear mode shape given in Figures 3 and 4 , in which the taper ratio parameter " $e$ " increases from 0.1 to 0.3 by a step of 0.1 . The effect of the section ratio $u_{1}$ for the tapered beam (b) is illustrated in Figure 5 via backbone curves associated with the first nonlinear mode shape, for $u_{1}$ varying from 0.4 to 0.8 by a step of 0.2 .

Figures 3 and 4 illustrate the effect on the nonlinear behaviour of the tapered beams (a) and (b) when the taper ratio " $e$ " varies from 0.1 to 0.3 . It can be noticed that the frequency ratios increase with increasing "e." Furthermore, nonlinear behaviour of the hardening type is obtained for all of the configurations presented. Figure 5 shows the effect of varying the section ratio on the behaviour of beam (b), in which the section ratio $u_{1}$ increases from 0.4 to 0.8 . With 
TABLE 1: The first five nondimensional natural frequencies of clamped tapered beams (a) with $S(x)=S_{1}(1-\alpha(x / L))$

\begin{tabular}{|c|c|c|c|c|c|c|c|c|c|c|}
\hline & \multicolumn{5}{|c|}{ Mode index } & \multirow{2}{*}{$\alpha$} & \multirow{2}{*}{$k_{t 1}$} & \multirow{2}{*}{$k_{t 2}$} & \multirow{2}{*}{$k_{\theta 1}$} & \multirow{2}{*}{$k_{\theta 2}$} \\
\hline & 1 & 2 & 3 & 4 & 5 & & & & & \\
\hline \multirow{4}{*}{$\begin{array}{l}\text { Present work } \\
\text { [34] } \\
\text { Present work } \\
{[34]}\end{array}$} & 11.8416 & 32.4754 & 63.5117 & 104.867 & 156.553 & \multirow{2}{*}{0.8} & & \multirow{4}{*}{$+\infty$} & \multirow{4}{*}{$+\infty$} & \multirow{4}{*}{$+\infty$} \\
\hline & 11.8417 & 32.4755 & 63.5118 & 104.867 & 156.554 & & & & & \\
\hline & 16.3355 & 44.9775 & 88.1180 & 145.614 & 217.487 & \multirow{2}{*}{0.5} & $+\infty$ & & & \\
\hline & 16.3356 & 44.9806 & 88.1382 & 145.665 & 217.572 & & & & & \\
\hline
\end{tabular}

TABLE 2: The first five nondimensional natural frequencies for simply supported tapered beams (a) with $S(x)=S_{1}(1-\alpha(x / L))$.

\begin{tabular}{|c|c|c|c|c|c|c|c|c|c|c|}
\hline & & & Mode ind & & & & & & & \\
\hline & 1 & 2 & 3 & 4 & 5 & $\alpha$ & $k_{t 1}$ & $k_{t 2}$ & $k_{\theta 1}$ & $k_{\theta 2}$ \\
\hline Present work & 4.91976 & 21.3444 & 47.481 & 83.8216 & 130.436 & 08 & & & & \\
\hline$[34]$ & 4.91976 & 21.3445 & 47.482 & 83.8216 & 130.436 & & $+\infty$ & & 0 & 0 \\
\hline Present work & 7.12153 & 28.9517 & 64.9771 & 115.345 & 180.080 & 05 & $+\infty$ & $+\infty$ & & 0 \\
\hline$[34]$ & 7.12153 & 28.9518 & 64.9788 & 115.351 & 180.089 & 0.5 & & & & \\
\hline
\end{tabular}

TABLE 3: The first five nondimensional natural frequencies of clamped tapered beams (b) with $S(x)=S_{1}(1-\alpha(x / L))^{2}$.

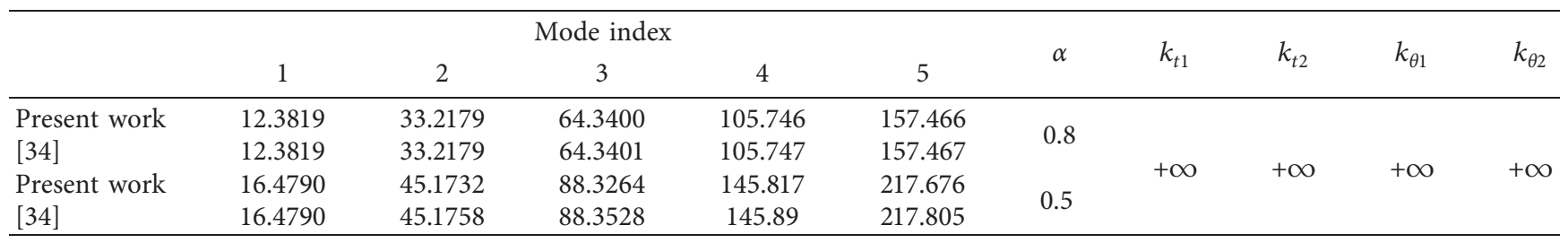

TABLE 4: The first five nondimensional natural frequencies of simply supported tapered beams (b) with $S(x)=S_{1}(1-\alpha(x / L))^{2}$.

\begin{tabular}{|c|c|c|c|c|c|c|c|c|c|c|}
\hline & \multicolumn{5}{|c|}{ Mode index } & \multirow{2}{*}{$\alpha$} & \multirow{2}{*}{$k_{t 1}$} & \multirow{2}{*}{$k_{t 2}$} & \multirow{2}{*}{$k_{\theta 1}$} & \multirow{2}{*}{$k_{\theta 2}$} \\
\hline & 1 & 2 & 3 & 4 & 5 & & & & & \\
\hline Present work & 4.35267 & 21.9378 & 48.4029 & 84.9297 & 131.665 & \multirow{2}{*}{0.8} & \multirow{4}{*}{$+\infty$} & \multirow{4}{*}{$+\infty$} & \multirow{4}{*}{0} & \multirow{4}{*}{0} \\
\hline$[34]$ & 4.35267 & 21.9379 & 48.4030 & 84.9298 & 131.666 & & & & & \\
\hline Present work & 6.95659 & 29.1104 & 65.2256 & 115.638 & 180.397 & \multirow{2}{*}{0.5} & & & & \\
\hline$[34]$ & 6.95659 & 29.1103 & 65.2277 & 115.647 & 180.413 & & & & & \\
\hline
\end{tabular}

TABLE 5: Nonlinear and linear frequency ratios for a tapered beams, with a varying depth and a taper ratio $\alpha=0.4$ and $r=\sqrt{I / S}$.

\begin{tabular}{|c|c|c|c|c|c|c|}
\hline & $W_{\max } / r$ & Present work & [19] & Rel diff [19] \% & {$[20]$} & Rel diff [20] \% \\
\hline \multirow{7}{*}{ SS-SS } & 0.2 & 1.0043 & 1.0042 & 0.01 & 1.0052 & 0.08 \\
\hline & 0.4 & 1.0174 & 1.0169 & 0.05 & - & - \\
\hline & 0.6 & 1.0386 & 1.0375 & 0.11 & 1.0436 & 0.47 \\
\hline & 0.8 & 1.0676 & 1.0658 & 0.17 & - & - \\
\hline & 1 & 1.1039 & 1.1011 & 0.26 & 1.1149 & 0.98 \\
\hline & 2 & 1.3671 & 1.3601 & 0.51 & 1.3835 & 1.18 \\
\hline & 3 & 1.7147 & 1.7065 & 0.47 & 1.7117 & 0.17 \\
\hline \multirow{7}{*}{$\mathrm{C}-\mathrm{C}$} & 0.2 & 1.0015 & 1.0017 & 0.01 & 1.0015 & 0.004 \\
\hline & 0.4 & 1.0060 & 1.0066 & 0.04 & - & - \\
\hline & 0.6 & 1.0136 & 1.0149 & 0.12 & 1.0134 & 0.02 \\
\hline & 0.8 & 1.0240 & 1.0263 & 0.21 & - & - \\
\hline & 1 & 1.0373 & 1.0408 & 0.33 & 1.0366 & 0.07 \\
\hline & 2 & 1.1416 & 1.1545 & 1.11 & 1.1366 & 0.44 \\
\hline & 3 & 1.2960 & 1.3224 & 1.90 & 1.2801 & 1.23 \\
\hline
\end{tabular}


TABLE 6: The beams size obtained after varying the taper ratio parameter "e."

\begin{tabular}{|c|c|c|c|c|c|c|}
\hline \multirow{2}{*}{ Beam } & \multicolumn{6}{|c|}{ Ratios } \\
\hline & $e$ & $u_{1}$ & $v_{1}$ & $z_{1}$ & $\alpha_{1}$ & $\alpha_{2}$ \\
\hline \multirow{3}{*}{ (a) } & 0.1 & 0.90 & 0.729 & 0.94868 & 0.2222 & 0.2 \\
\hline & 0.2 & 0.80 & 0.512 & 0.89442 & 0.5000 & 0.4 \\
\hline & 0.3 & 0.70 & 0.343 & 0.83666 & 0.8571 & 0.6 \\
\hline \multirow{3}{*}{ (b) } & 0.1 & 0.81 & 0.656 & 0.94868 & 0.2222 & 0.2 \\
\hline & 0.2 & 0.64 & 0.409 & 0.89442 & 0.5000 & 0.4 \\
\hline & 0.3 & 0.49 & 0.240 & 0.83666 & 0.8571 & 0.6 \\
\hline
\end{tabular}

TABLE 7: The beam (b) size obtained after varying the section ratio " $u_{1} . "$

\begin{tabular}{|c|c|c|c|c|c|}
\hline \multirow{2}{*}{ Beam } & \multicolumn{5}{|c|}{ Ratios } \\
\hline & $u_{1}$ & $v_{1}$ & $z_{1}$ & $\alpha_{1}$ & $\alpha_{2}$ \\
\hline \multirow{3}{*}{ (b) } & 0.4 & 0.16 & 0.79527 & 1.16227 & 0.73508 \\
\hline & 0.6 & 0.36 & 0.88011 & 0.58198 & 0.45080 \\
\hline & 0.8 & 0.64 & 0.94574 & 0.23606 & 0.21114 \\
\hline
\end{tabular}

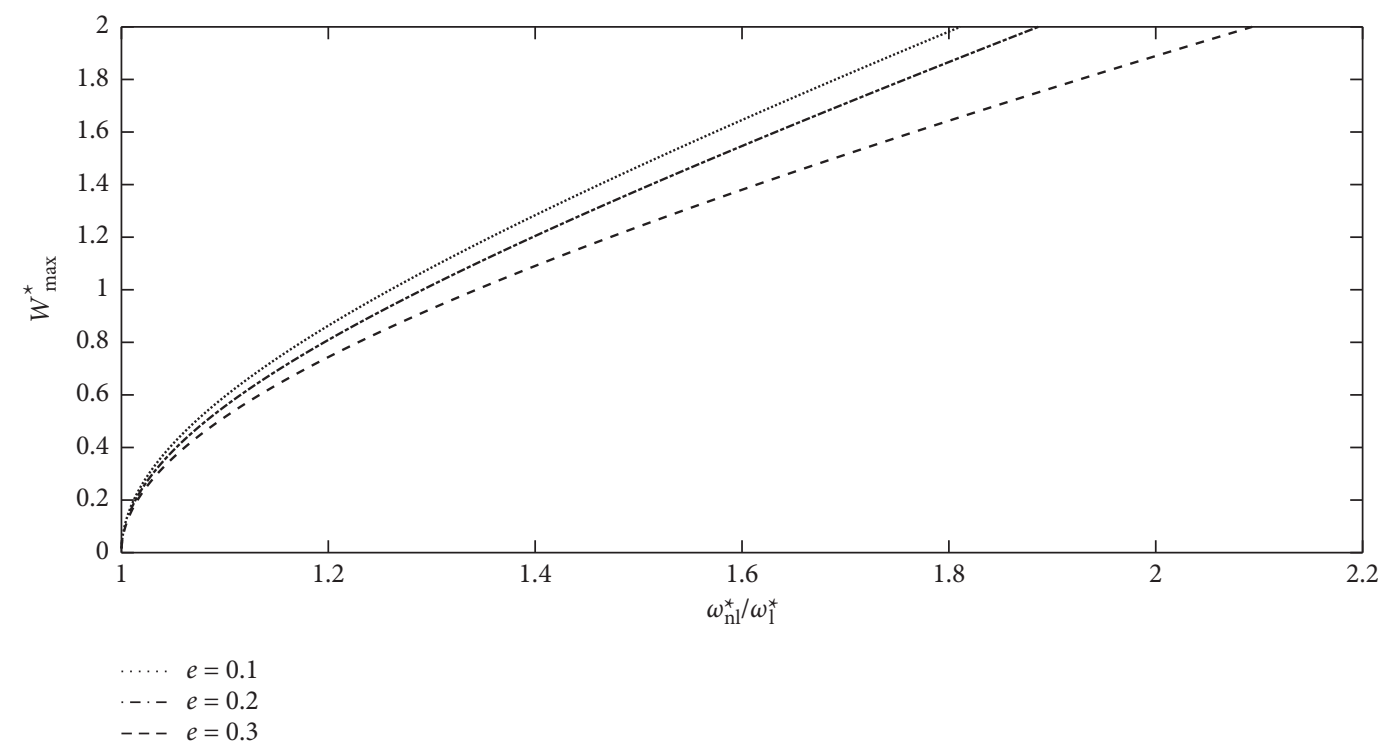

FIGURE 3: Backbone curves of a clamped tapered beam (a) in the vicinity of the first mode for various values of "e."

increasing $u_{1}$, the frequency ratio decreases relatively to a maximum nondimensional amplitude equal to 2 . It can be seen that the hardening behaviour is higher for $u_{1}=0.4$ compared to the other values.

Figures 6-11 illustrate the bending moments derived from the linear and nonlinear models of the tapered beams (a) and (b), where the taper ratio parameter " $e$ " is increased from 0.1 to 0.3 , leading to six scenarios. The maximum nondimensional amplitudes $W_{\max }^{*}$ of each scenario varies from 0.5 to 2 in steps of 0.5 . Tables $8-10$ summarize the numerical values of the bending moment as estimated by the linear and nonlinear theories at different locations and their corresponding percentage correction. It is indicated that the summarized results are for a maximum nondimensional amplitude of 2 .

Figures 6-11 show that by increasing $W_{\max }^{*}$, the gap between the linear and nonlinear bending moments increases in all the studied scenarios. When the taper ratio parameter " $e$ " takes the value 0.1 , the bending moments of the beam (a) at the clamps obtained via the linear theory are higher than that obtained via the nonlinear theory. However, if the taper ratio parameter is increased to 0.3 , the nonlinear bending moment becomes higher than that predicted by linear theory. In the other cases, the bending moments of the beam (b) obtained at the clamps and via the nonlinear theory are always higher than those obtained via the linear theory. Moreover, these figures show that the superposition principle used in many studies including [39, 40], based on the linear theory, cannot be used, as may be expected, to predict the nonlinear bending moment distribution. In other terms, when $W_{\max }^{*}=1$ is multiplied by 2 , its associated linear bending moment at each point is multiplied by 2 . The superposition is respected in the linear case, but on the other side, the nonlinear bending moment does not undergo the 


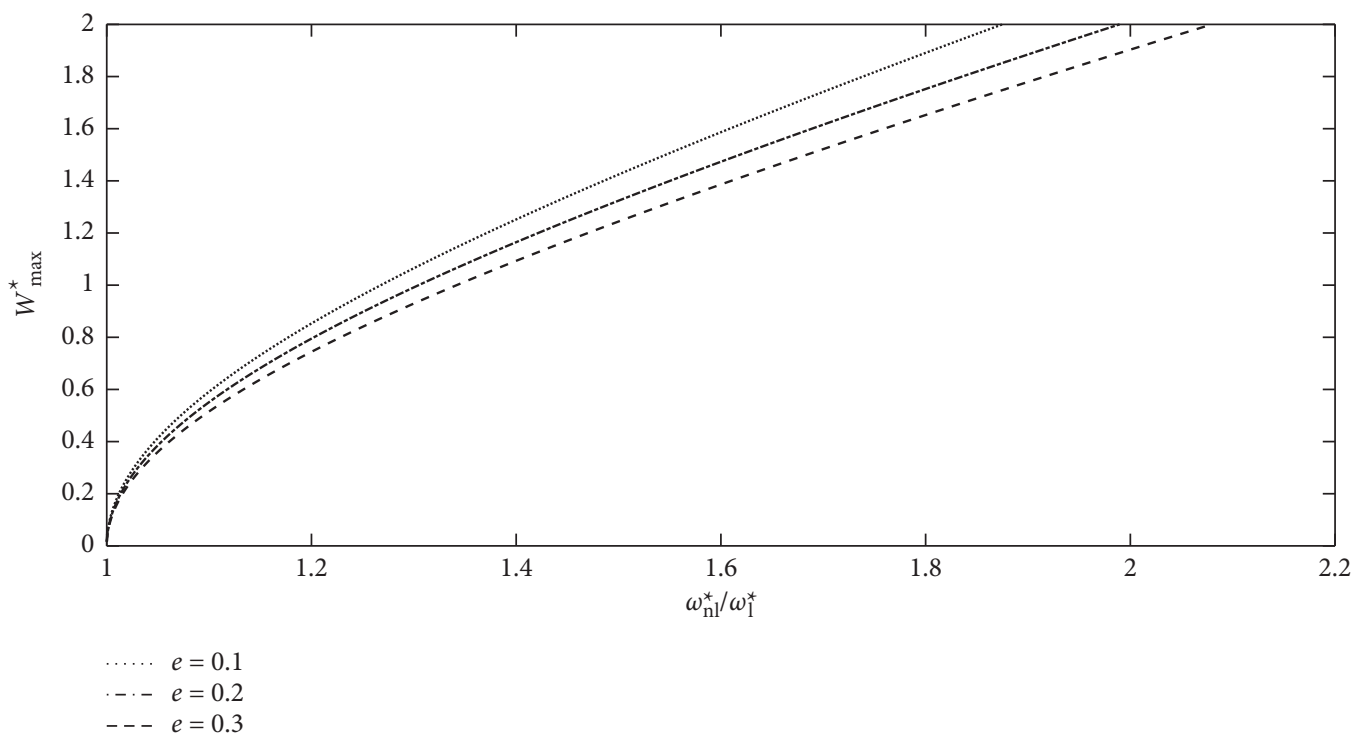

FIgURE 4: Backbone curves of a clamped tapered beam (b) in the vicinity of the first mode for various values of "e."

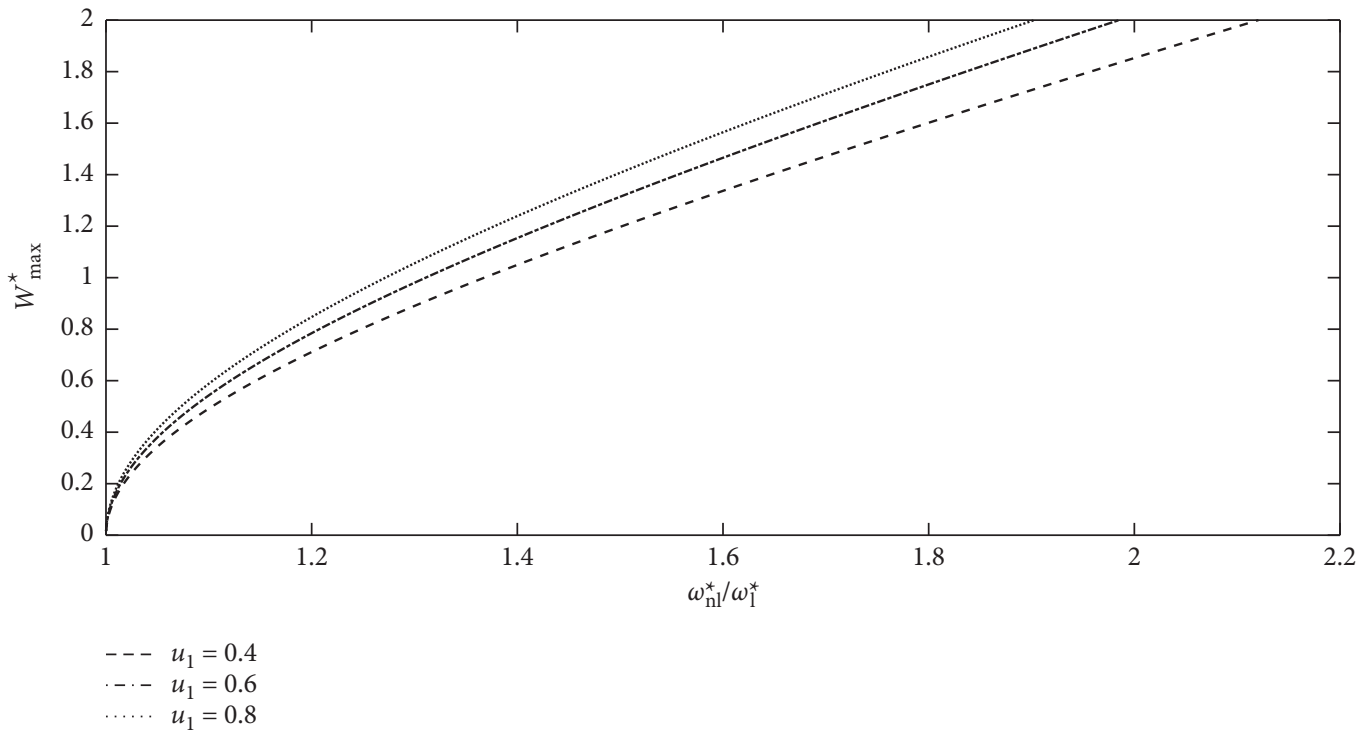

Figure 5: Backbone curves of a clamped tapered beam (b) in the vicinity of the first mode for various values of " $u_{1}$."

same variation. Its distribution is not multiplied by 2 , as shown especially in Figures 9-11, in which the nonlinear bending moment in the middle (the beam step location) remains much smaller than in the linear case. From these observations, it can be observed that the nonlinear bending moment distribution cannot be predicted by the superposition method, hence the interest of using the nonlinear theory.

On the other hand, Tables $8-10$ show that there may be a considerable percentage correction between linear and nonlinear results. For a taper ratio parameter equal to 0.1 , this percentage reaches $58.30 \%$ for beam (a) and $31.11 \%$ for beam (b). Similarly, for a taper ratio parameter equal to 0.2 , this percentage reaches $41.71 \%$ for beam (a) and $33.71 \%$ for beam (b). Finally, for a taper ratio parameter equal to 0.3 , this percentage reaches $40.23 \%$ for beam (a) and $35.68 \%$ for beam (b). These results highlight that the use of linear theory can be misleading. Also, a change in the location of the maximum bending moment should be noticed as shown in Table 9, where for beam (a), the maximum bending moment is located at the clamps in the linear case while it is located at the middle point of the beam in the nonlinear case. Also, the same change can be observed in Table 10. However, in beam (b), where the maximum bending moment obtained by the linear theory is located at the middle while it is located at the clamps in the nonlinear case.

3.2. Nonlinear Forced Vibration. In the present section, the nonlinear forced dynamic behaviour is examined for beams (a) and (b). Each beam is supposed to be subjected to a point harmonic force applied at its middle point. The effects of the 


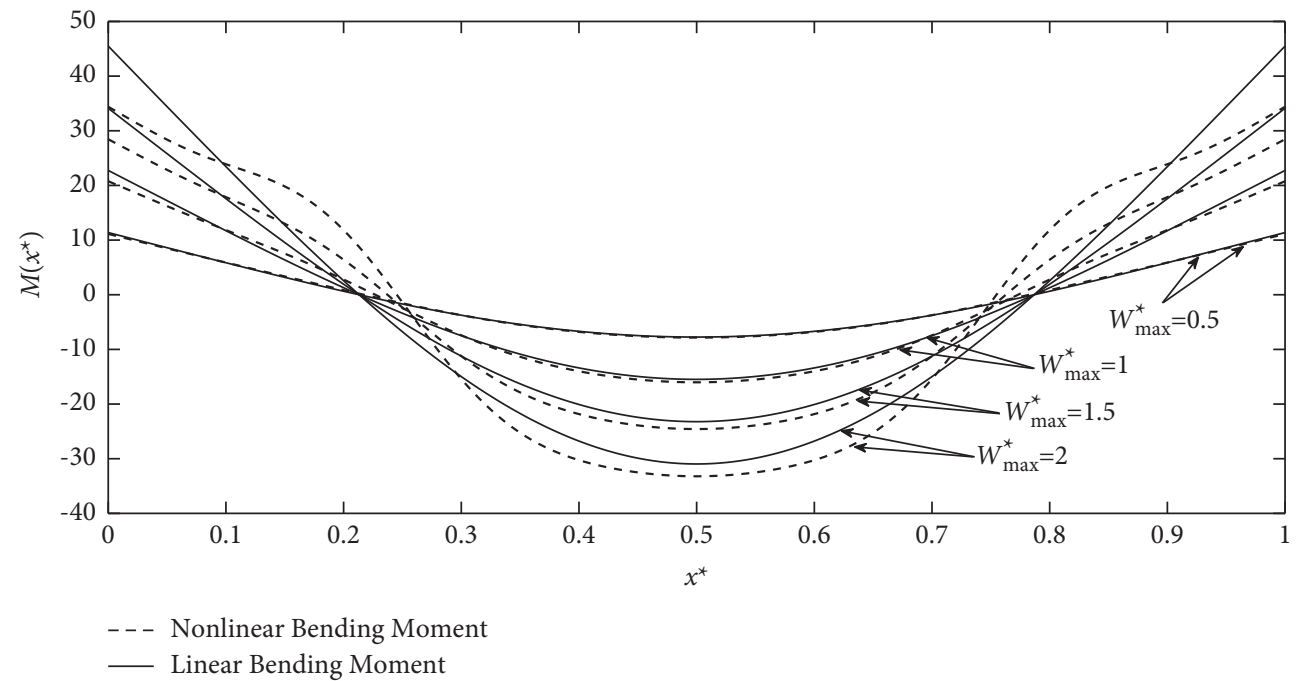

Figure 6: The linear and nonlinear bending moments of the beam (a) with $e=0.1$ for different values of $W_{\max }^{*}$.

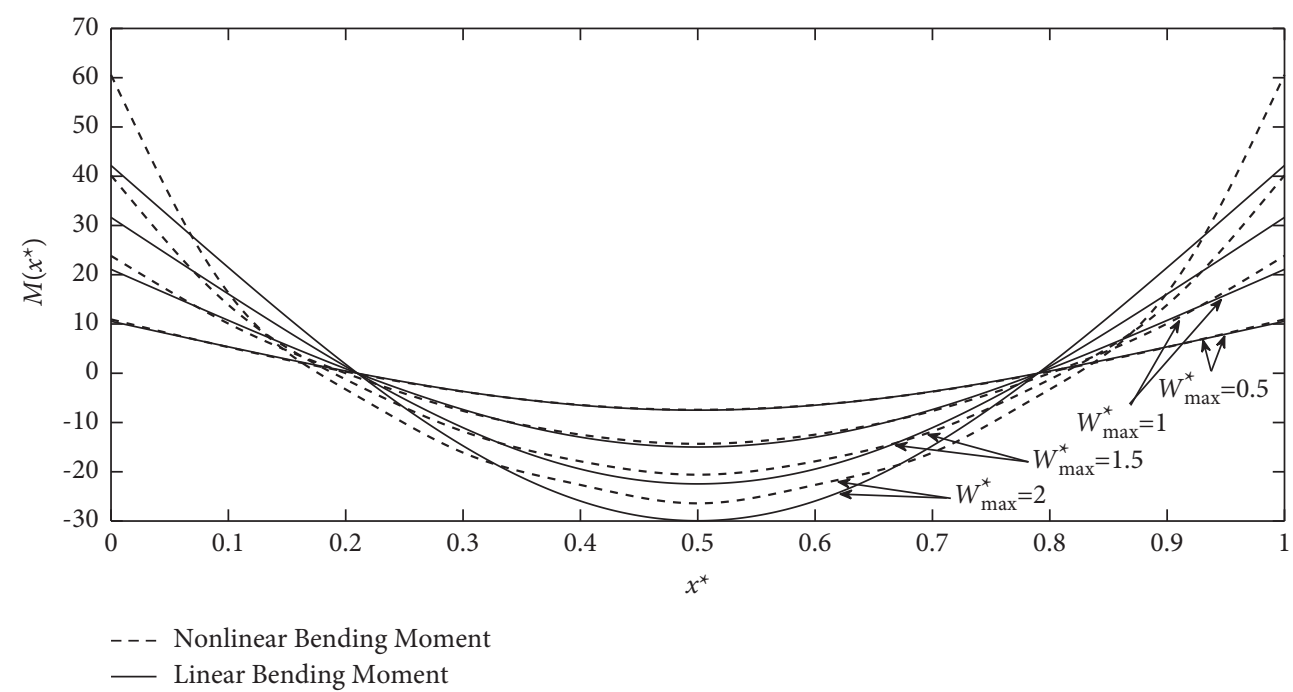

FIgURE 7: The linear and nonlinear bending moments of the beam (b) with $e=0.1$ for different values of $W_{\max }^{*}$.

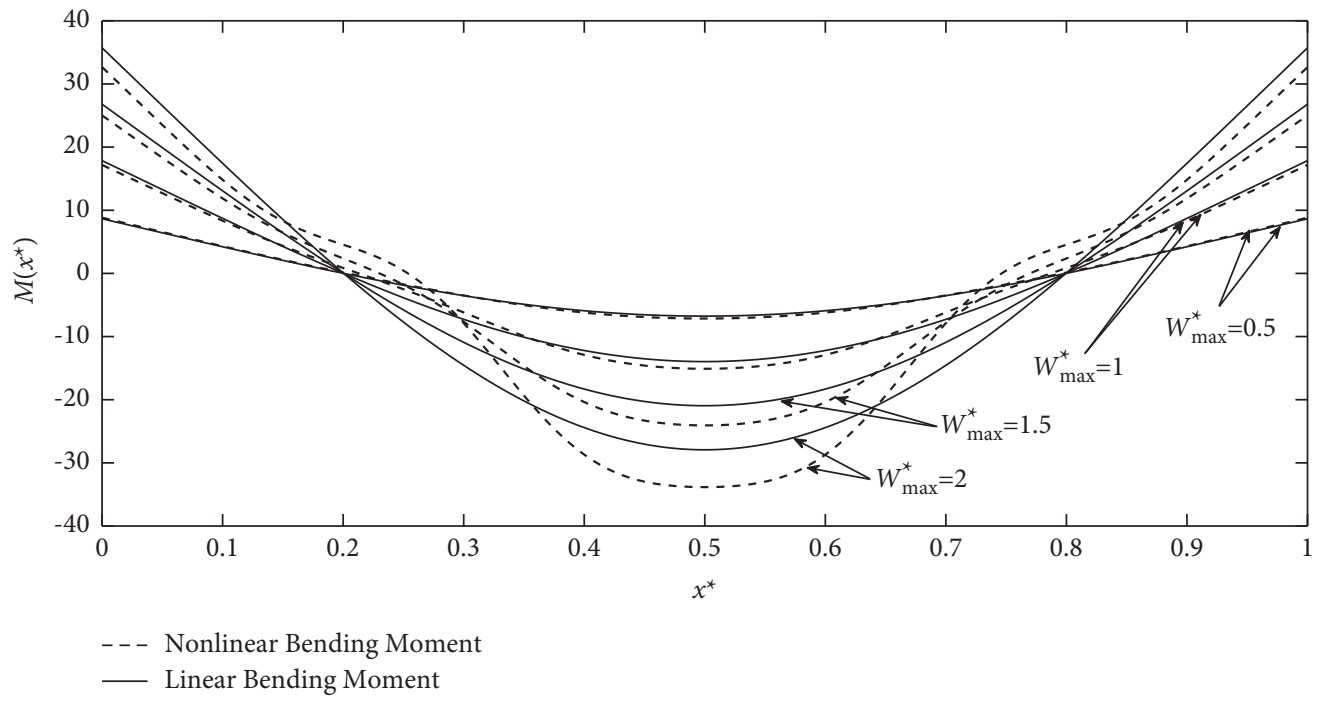

Figure 8: The linear and nonlinear bending moments of the beam (a) with $e=0.2$ for different values of $W_{\max }^{*}$. 


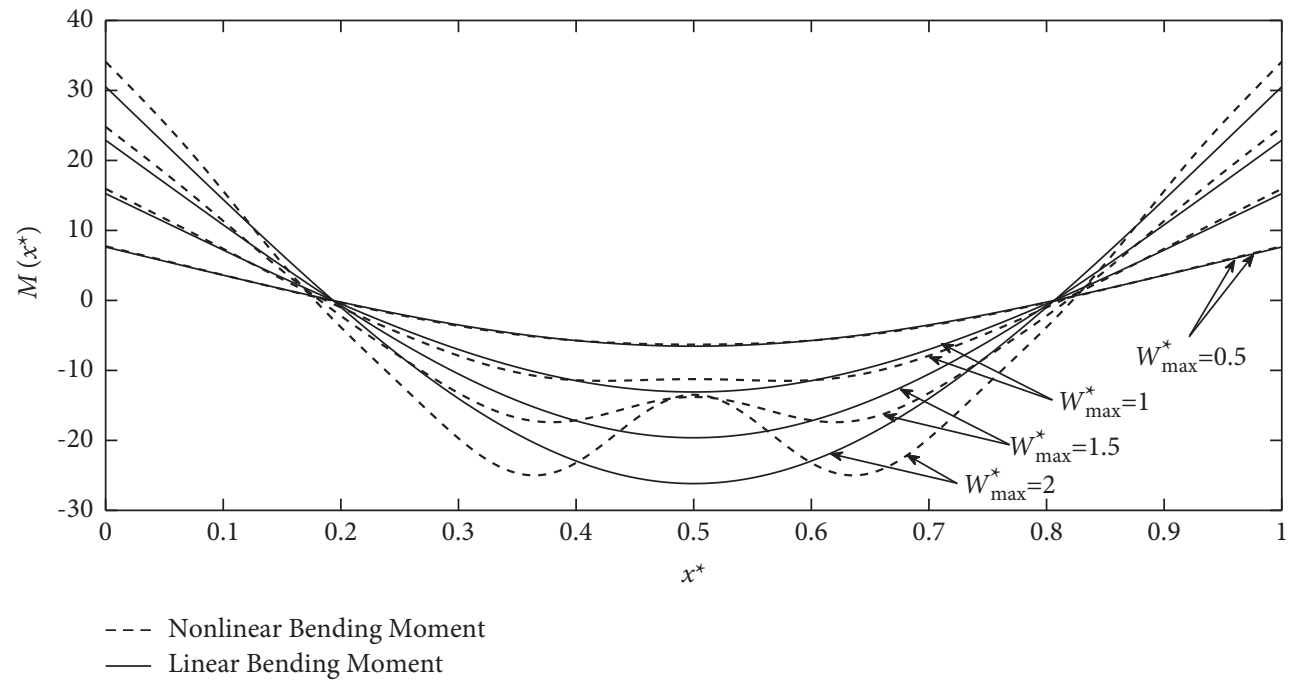

Figure 9: The linear and nonlinear bending moments of the beam (b) with $e=0.2$ for different values of $W_{\max }^{*}$.

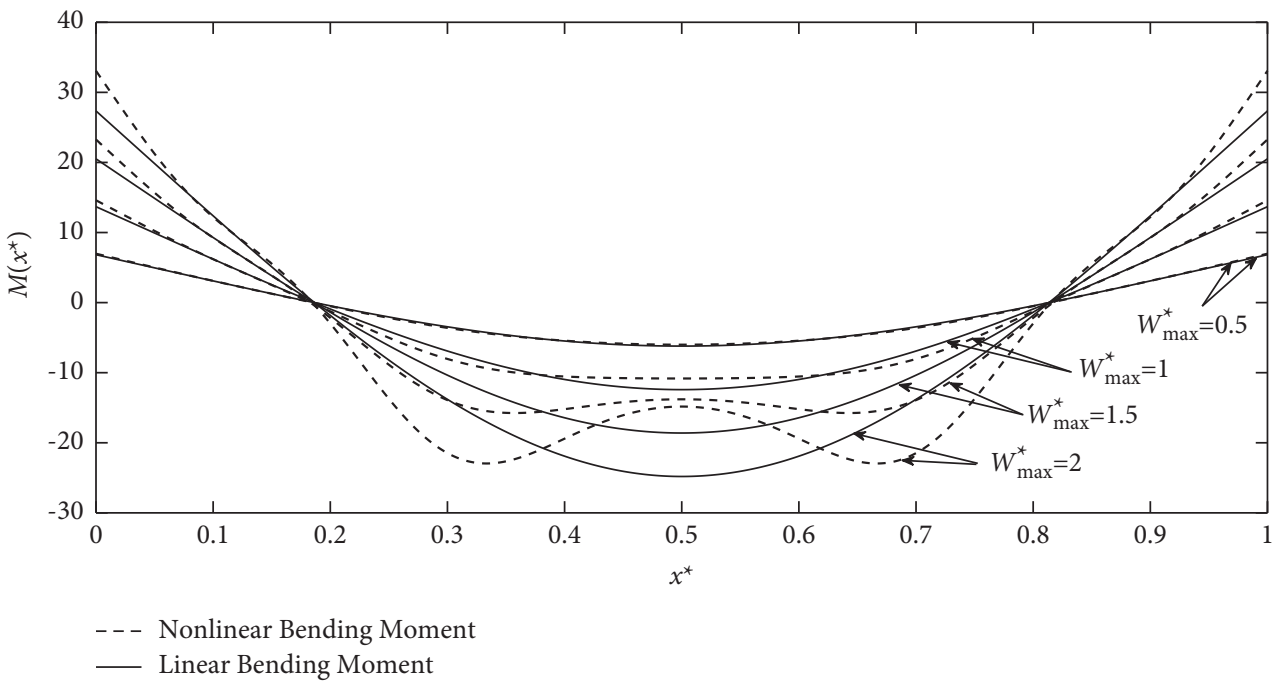

FIgURE 10: The linear and nonlinear bending moment of the beam (a) with $e=0.3$ for different values of $W_{\max }^{*}$.

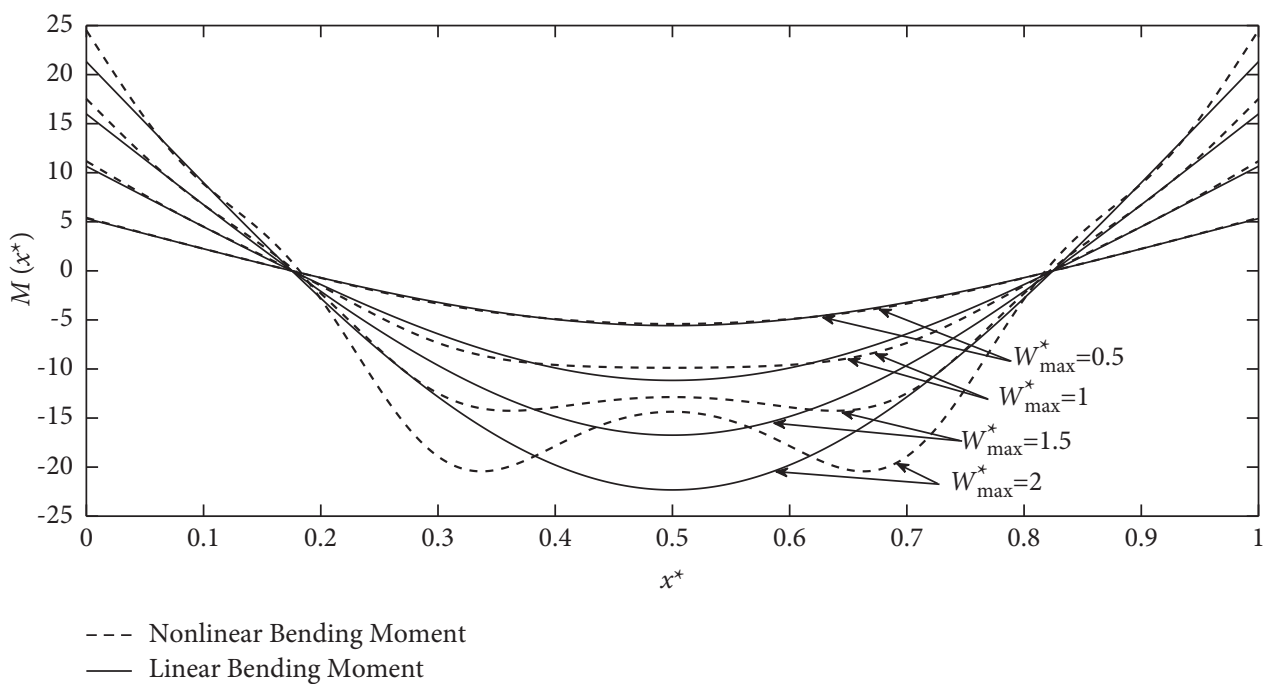

FIgURE 11: The linear and nonlinear bending moment of the beam (b) with $e=0.3$ for different values of $W_{\max }^{*}$. 
TABLE 8: Percentage correction between bending moment estimates via linear and nonlinear theories. Maximum nondimensional amplitude $W_{\max }^{*}=2$.

\begin{tabular}{|c|c|c|c|c|c|}
\hline \multirow[b]{2}{*}{$e$} & \multirow[b]{2}{*}{ Beam } & \multirow[b]{2}{*}{$x^{*}$} & \multicolumn{2}{|c|}{ Bending moment } & \multirow{2}{*}{ Percentage correction $\%$} \\
\hline & & & Nonlinear & Linear & \\
\hline \multirow{4}{*}{0.1} & \multirow{2}{*}{ (a) } & 0 & 34.39 & 45.49 & 32.27 \\
\hline & & 0.5 & -33.21 & -30.96 & 6.77 \\
\hline & \multirow{2}{*}{ (b) } & 0 & 60.57 & 42.18 & 30.35 \\
\hline & & 0.5 & -26.40 & -29.94 & 13.40 \\
\hline
\end{tabular}

TABle 9: Percentage correction between bending moment estimates via linear and nonlinear theories. Maximum nondimensional amplitudes $W_{\max }^{*}=2$.

\begin{tabular}{cccccc}
\hline & & \multicolumn{2}{c}{ Bending moment } & Percentage correction \% \\
\hline & Beam & $x^{*}$ & Nonlinear & Linear & 9.35 \\
0.2 & (a) & 0 & 32.66 & 35.72 & 17.46 \\
& & 0.5 & -33.83 & -27.92 & 10.48 \\
& (b) & 0 & 34.10 & 30.52 & 48.49 \\
\hline
\end{tabular}

TABle 10: Percentage correction between bending moment estimates via linear and nonlinear theories. Maximum nondimensional amplitudes $\left(W_{\max }^{*}=2\right)$.

\begin{tabular}{cccccc}
\hline \multicolumn{1}{c}{} & \multicolumn{2}{c}{ Bending moment } & Percentage correction \% \\
\hline & Beam & $x^{*}$ & Nonlinear & Linear & 17.31 \\
0.3 & (a) & 0 & 33.07 & 27.34 & 40.21 \\
& & 0.5 & -14.83 & -24.80 & 13.02 \\
& (b) & 0.5 & -14.35 & -22.31 & 35.68 \\
\hline
\end{tabular}

taper ratio, the cross section area, the inertia, and the excitation level are investigated. Before determining the forced response via the formulation developed above, it is necessary to identify the predominant mode associated with the applied excitation force to perform the analysis in its vicinity. For this purpose, the generalized forces are calculated and presented in Table 11 showing that the first vibration mode remains predominant. The study will then be conducted in its neighborhood.

Figure 12 shows the linear and nonlinear frequency response functions in the vicinity of the first mode of the beam (a), with a taper ratio equal to 0.1 , excited by a centered point force $F^{c}=10$. The nonlinear hardening effect and the multivalue regions in which the jump phenomenon may occur can be clearly observed.

The effect of the taper ratio on the forced response to a centred point forces $F^{c}=10$, applied at the middles of beams (a) and (b), can be seen in Figures 13 and 14. The nonlinear frequency response functions are given in the neighborhood of the predominant mode, for a taper ratio parameter $e$ increased from 0.1 to 0.3 by a step of 0.1 . It can be clearly observed that by increasing $e$, the nonlinear hardening effect increases for both beams.

The hardening effect is also more apparent in the nonlinear frequency response functions of beam (a) compared to beam (b). It can be seen that the gap between the result obtained when $e=0.1$ and $e=0.3$ for beam (a) is larger than the gap observed for beam (b).

The effect of the section ratio $u_{1}$ is studied for beam (b) and illustrated in Figure 15 through the nonlinear frequency response functions associated with the predominant nonlinear mode shape, in which the section ratio $u_{1}$ varies from 0.4 to 0.8 by a step of 0.2 . This beam is excited by a concentrated force $F^{c}=10$.

Figure 15 shows the effect of geometric nonlinearity as a function of cross section ratio. It can be noticed that by increasing $u_{1}$, the hardening effect decreases consequently. For $u_{1}=0.4$, when the vibration amplitude increases, the frequency ratio increases significantly compared to the other two values of $u_{1}$.

Figure 16 illustrates the nonlinear frequency response functions for beam (a) with $e=0.1$ excited by different levels of the concentric force applied to the middle, increasing as follows: $F^{c}=[0,10,100$ and 1000]. The same test is repeated for beam (b), leading to the results presented in Figure 17.

Figures 16 and 17 demonstrate the effect of varying the level of the applied forces. It can be seen that the frequency response increased disproportionately relative to the increase in the excitation intensity. Figures 18 and 19 illustrate the bending moments estimated by the linear and nonlinear theories for beams (a) and (b), with a taper ratio $e=0.1$ and $F^{c}=100$. Table 12 summarizes the numerical values of the 
TABLE 11: Percentage of generalized forces exciting the first five symmetric modes of a tapered beam subjected to a concentred force $F^{c}=10$ located at the beam middle.

\begin{tabular}{|c|c|c|c|c|c|}
\hline & \multicolumn{5}{|c|}{ Modes } \\
\hline & 1 & 3 & 5 & 7 & 9 \\
\hline$F^{c} w_{i}^{*}\left(x_{c}\right)$ & 15.875 & 13.893 & 13.969 & 13.963 & 13.961 \\
\hline$F^{c} w_{i}^{*}\left(x_{c}\right) / \sum_{i=1}^{N}\left|F^{c} w_{i}^{*}\left(x_{c}\right)\right|$ & 22.152 & 19.386 & 19.493 & 19.484 & 19.482 \\
\hline
\end{tabular}

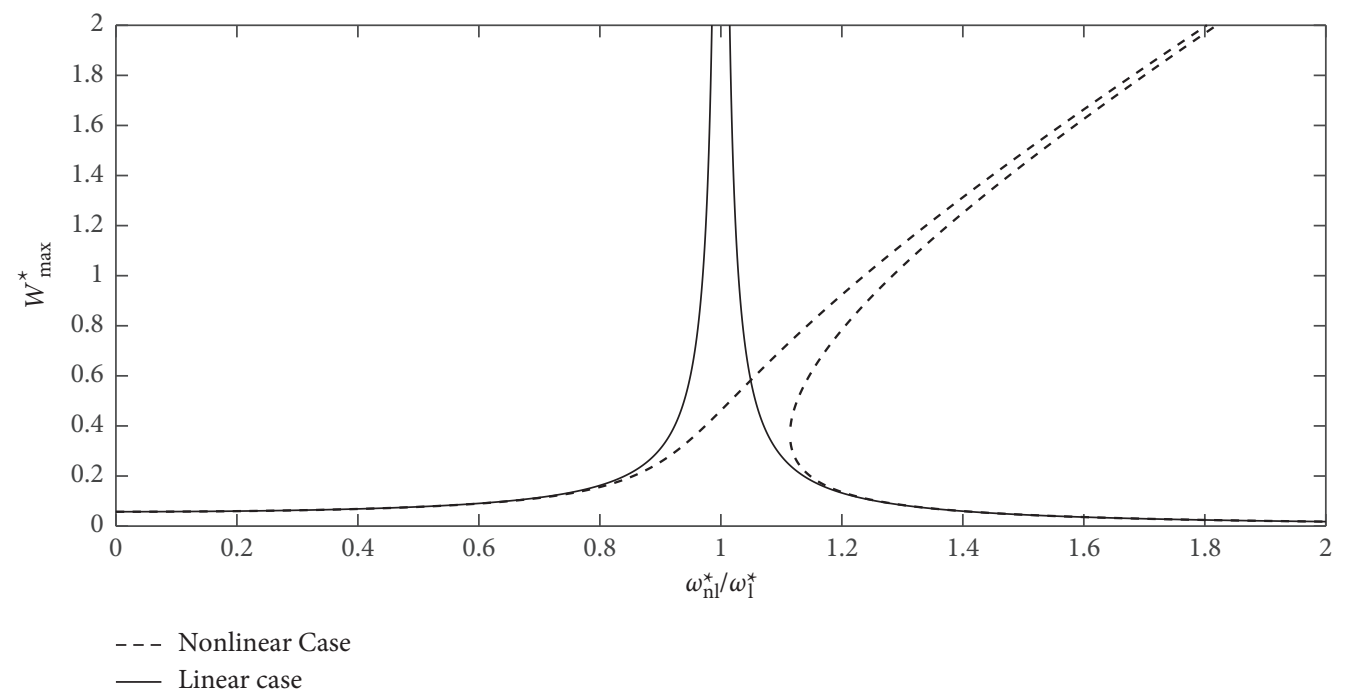

FigURe 12: Linear and nonlinear frequency response functions comparison for beam (a) with $e=0.1$ and $F^{c}=10$.

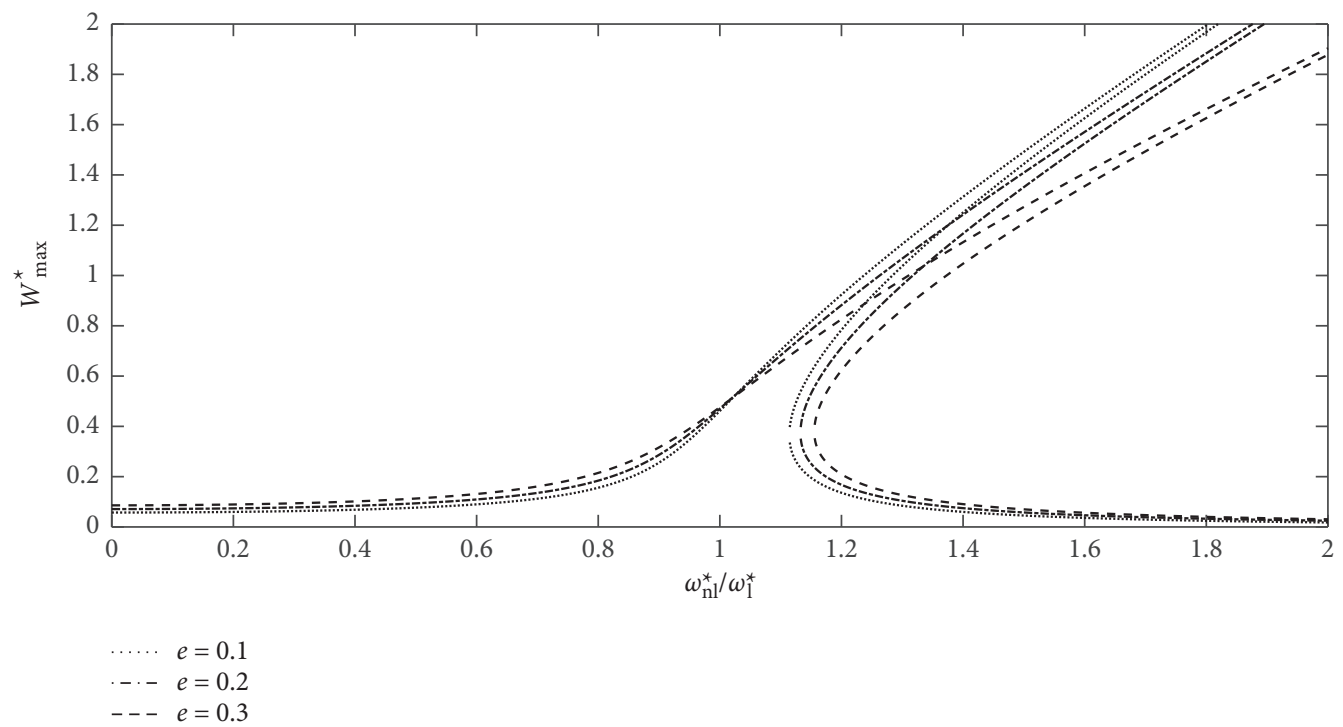

FIGURE 13: Nonlinear frequency response functions for tapered beam (a) with different values of " $e$," excited by a concentred force $F^{c}=10$.

bending moments estimated via the linear and nonlinear theories at two different locations, with the corresponding percentage correction. Considering that the maximum nondimensional amplitude $W_{\max }^{*}$ varies from 0.5 to 2 by a step of 0.5 in Figures 18, 19, and 12.

Figures 18 and 19, and Table 12 show the effect of varying $W_{\max }^{*}$ on the nonlinear dynamic behaviour of beams (a) and (b). It is remarkable that by increasing the value of $W_{\max }^{*}$, the difference between the linear and nonlinear results also increases, which also leads to an increase in the percentage correction of the bending moments. For $W_{\max }^{*}=0.5$ at $x^{*}=0$, this percentage is equal to $9.505 \%$ and $1.849 \%$ for beams (b) and (a), respectively, while for $W_{\max }^{*}=2$, the percentage correction of beams (a) and (b) increases, respectively, to $24.25 \%$ and $32.76 \%$. It can be noticed that the percentage correction of the bending moments at the ends is 


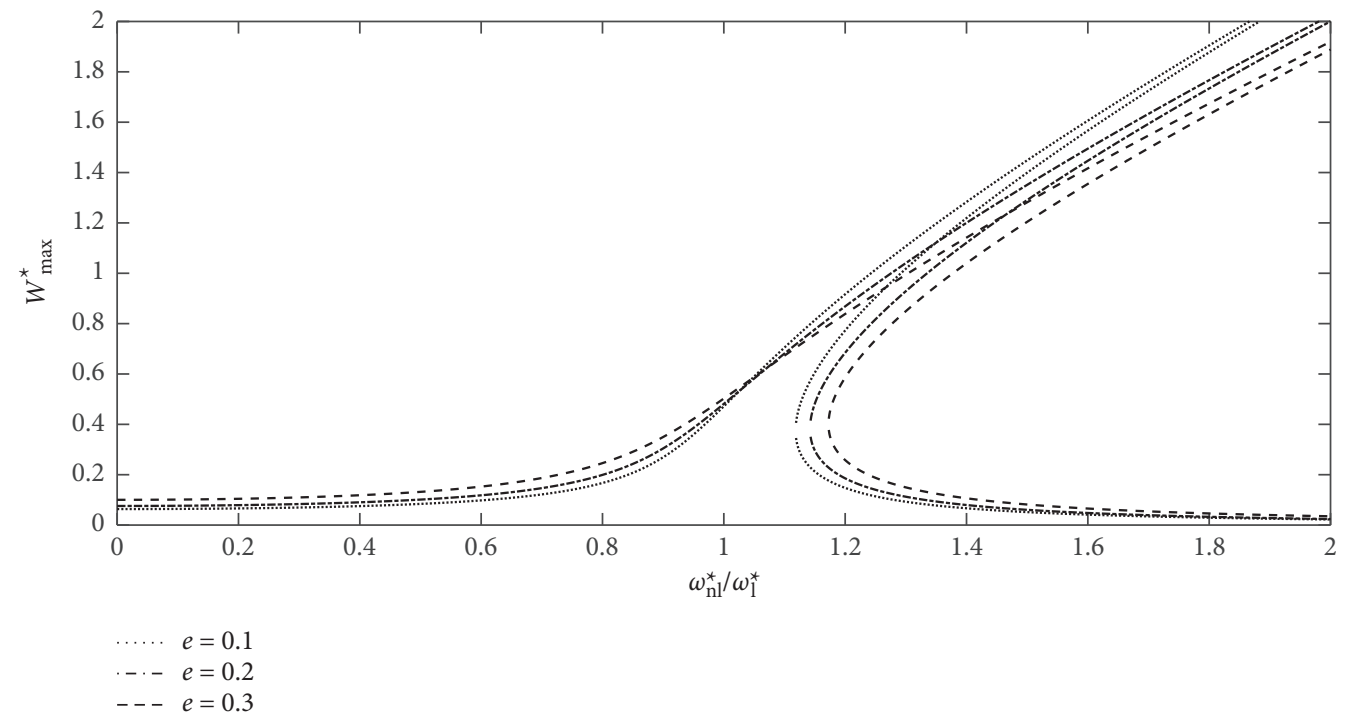

FIGURE 14: Nonlinear frequency response functions for tapered beam (b) with different values of " $e$," excited by a concentred force $F^{c}=10$.

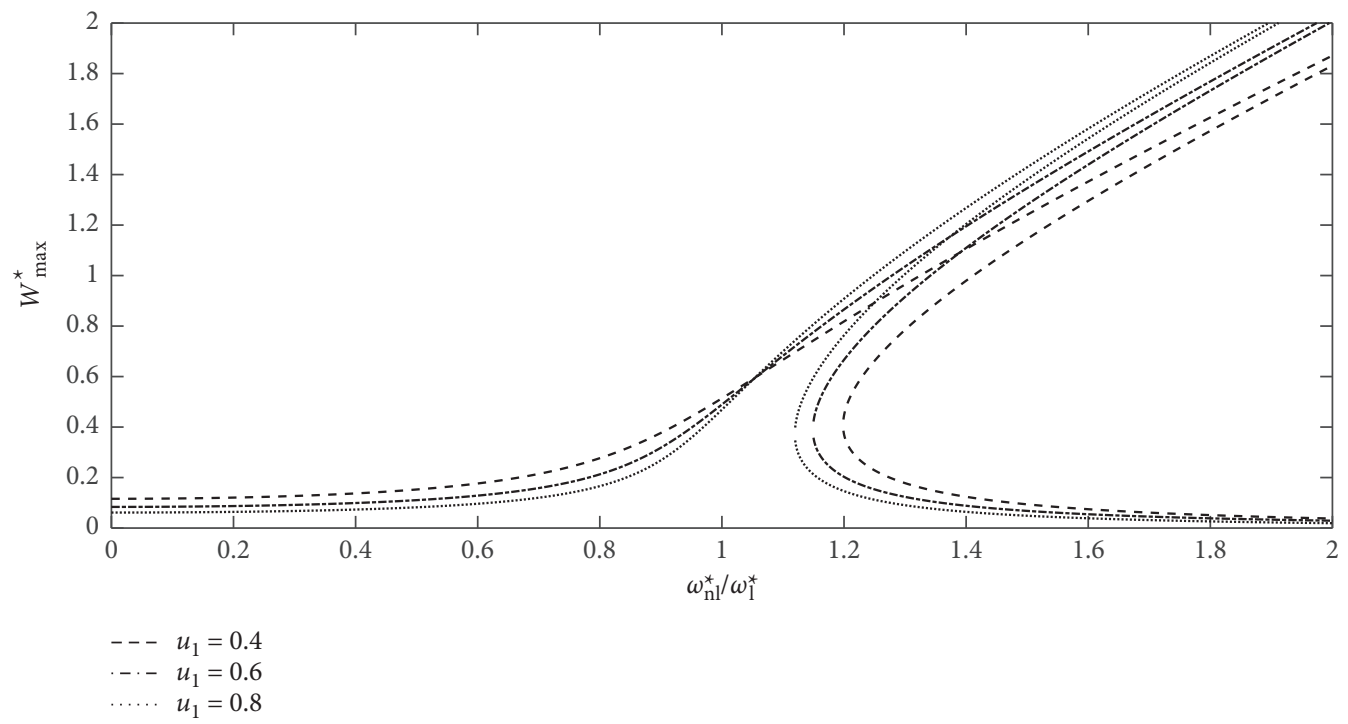

FIGURE 15: Nonlinear frequency response functions for beam (b) with different values of $u_{1}$ excited by a concentred force $F^{c}=10$.

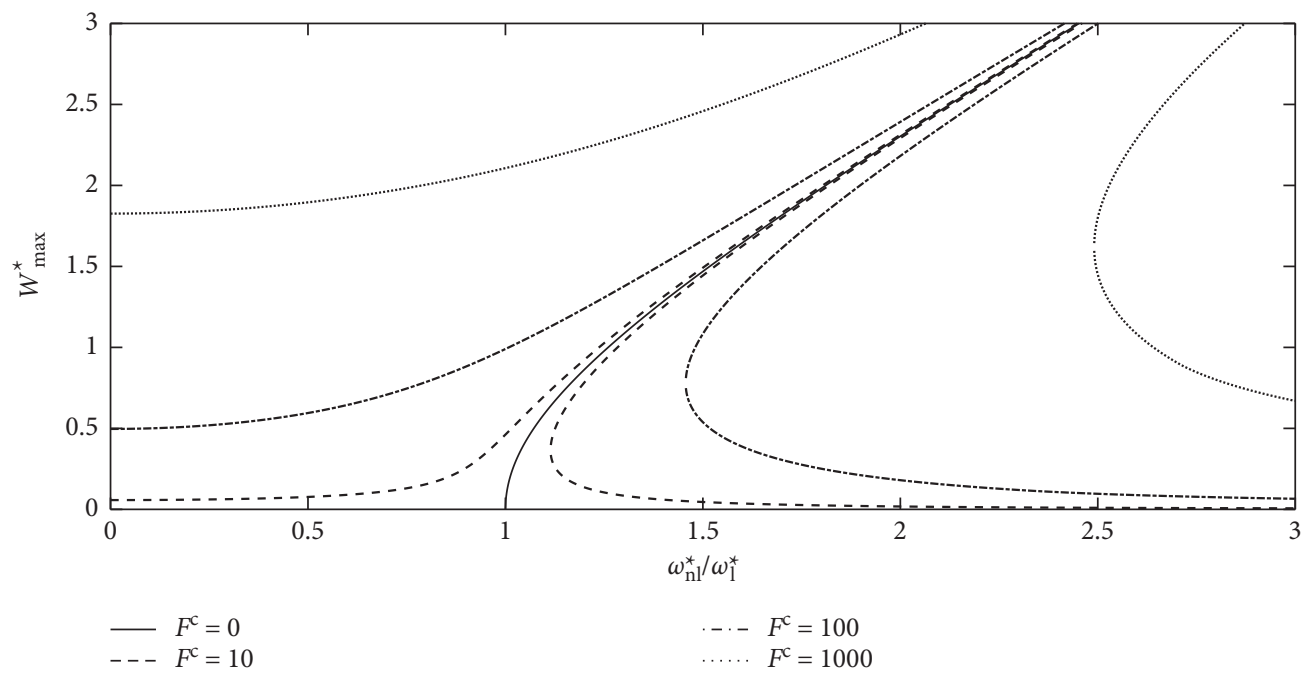

FIGURE 16: Nonlinear frequency response functions for beam (a) excited by different levels of $F^{c}$. 


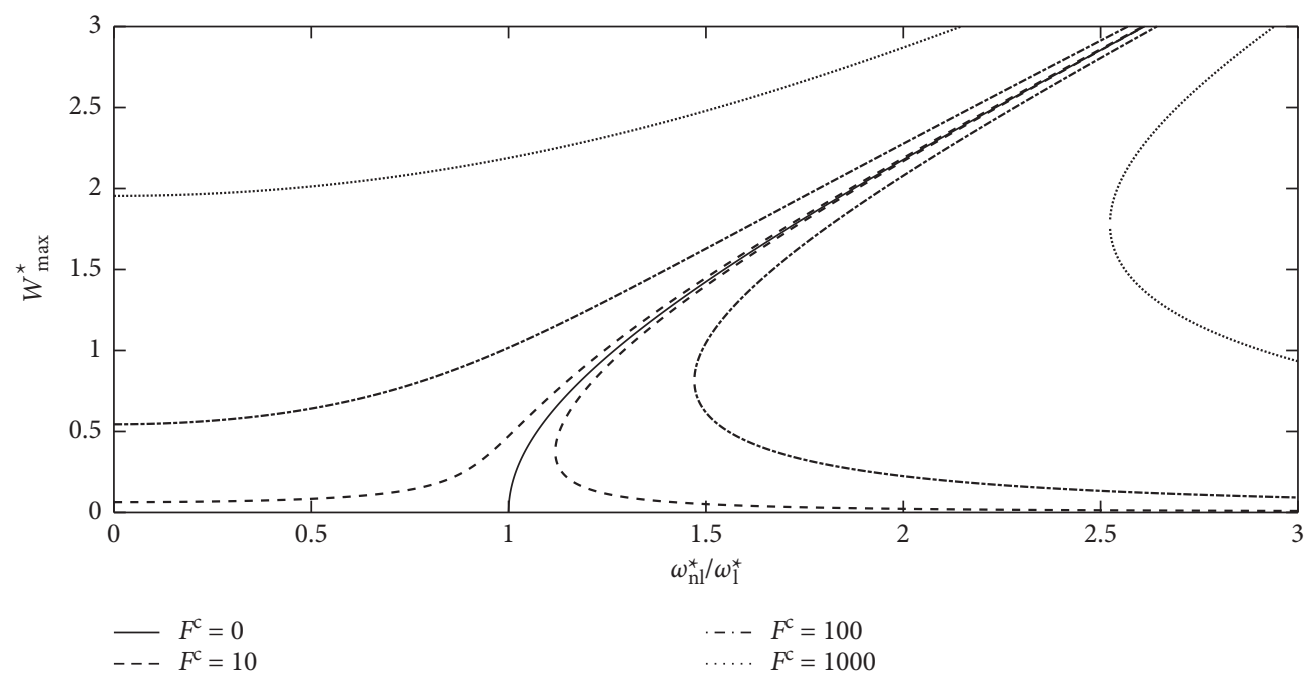

Figure 17: Nonlinear frequency response functions for beam (b) excited by different levels of $F^{c}$.

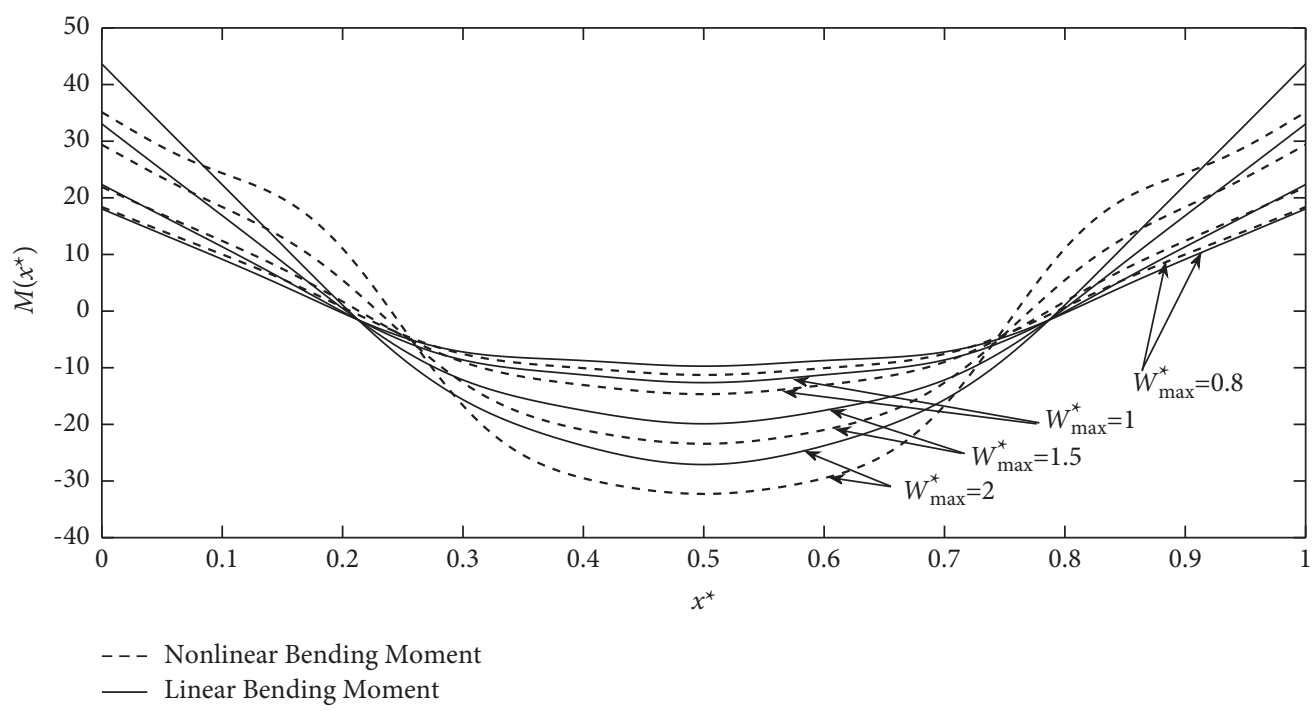

FIGURE 18: The linear and nonlinear bending moments of beam (a) with $e=0.1$, for various values of $W_{\max }^{*}$.

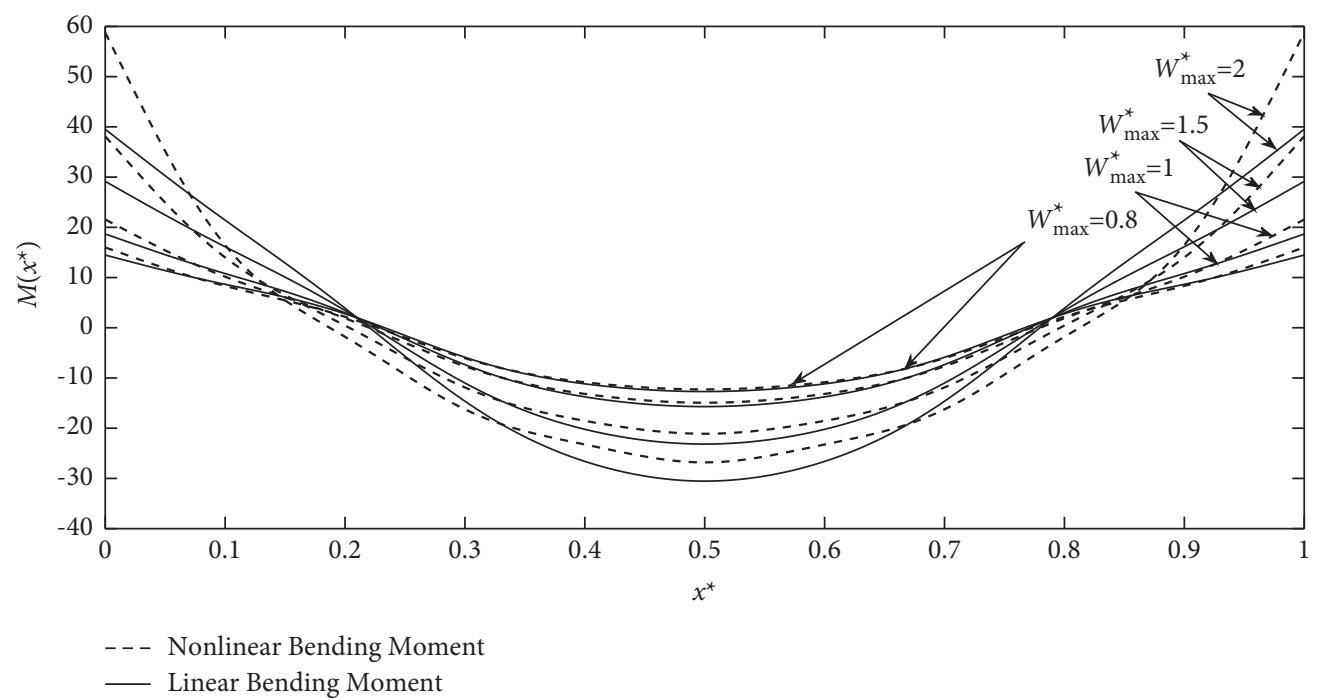

FIGURE 19: The linear and nonlinear bending moments of beam (b) with $e=0.1$, for various values of $W_{\max }^{*}$. 
TABLE 12: Percentage correction between bending moments estimated via the linear and nonlinear theories for the two beams with $e=0.1$.

\begin{tabular}{|c|c|c|c|c|c|}
\hline \multicolumn{6}{|c|}{ Bending moment } \\
\hline$W_{\max }^{*}$ & Beam & $x^{*}$ & Nonlinear & Linear & Percentage correction \% \\
\hline \multirow{4}{*}{0.8} & \multirow{2}{*}{ (a) } & 0 & 18.38 & 18.04 & 1.849 \\
\hline & & 0.5 & -11.27 & -9.721 & 13.74 \\
\hline & \multirow{2}{*}{ (b) } & 0 & 15.99 & 14.47 & 9.505 \\
\hline & & 0.5 & -12.26 & -12.70 & 3.588 \\
\hline \multirow{4}{*}{1} & \multirow{2}{*}{ (a) } & 0 & 21.92 & 22.34 & 1.916 \\
\hline & & 0.5 & -14.66 & -12.63 & 13.84 \\
\hline & \multirow{2}{*}{ (b) } & 0 & 21.55 & 18.67 & 13.36 \\
\hline & & 0.5 & -14.92 & -15.69 & 5.160 \\
\hline \multirow{4}{*}{1.5} & \multirow{2}{*}{ (a) } & 0 & 29.37 & 33.05 & 12.52 \\
\hline & & 0.5 & -23.42 & -19.89 & 15.07 \\
\hline & \multirow{2}{*}{ (b) } & 0 & 38.11 & 29.14 & 23.53 \\
\hline & & 0.5 & -21.10 & -23.15 & 9.715 \\
\hline \multirow{4}{*}{2} & \multirow{2}{*}{ (a) } & 0 & 35.12 & 43.64 & 24.25 \\
\hline & & 0.5 & -32.28 & -27.09 & 16.07 \\
\hline & \multirow{2}{*}{ (b) } & 0 & 58.78 & 39.52 & 32.76 \\
\hline & & 0.5 & -26.80 & -30.53 & 13.91 \\
\hline
\end{tabular}

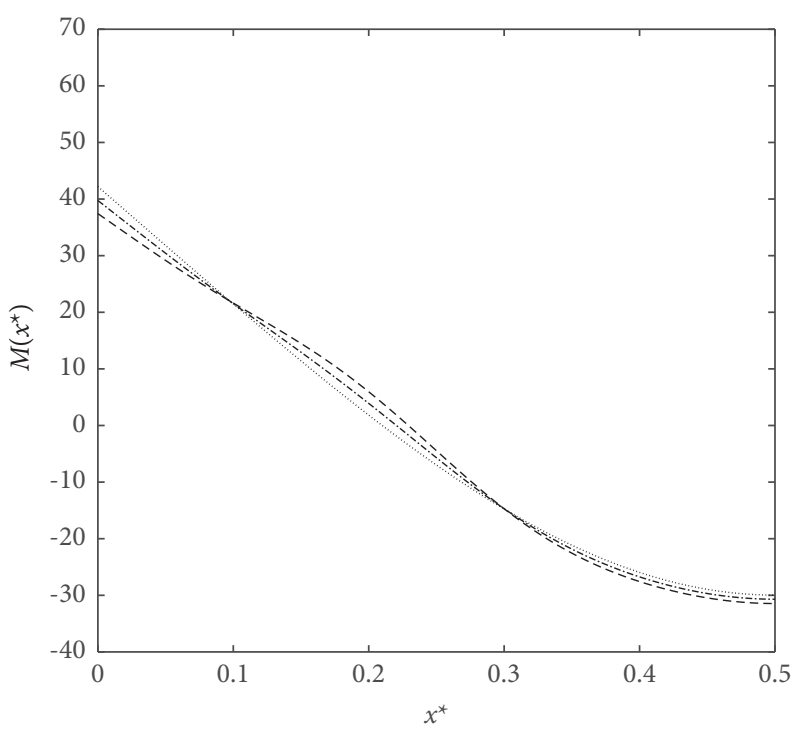

Linear Bending Moment

$$
\begin{aligned}
\ldots . . & F^{c}=0 \\
-\cdot-F^{c} & =100 \\
---F^{c} & =200
\end{aligned}
$$

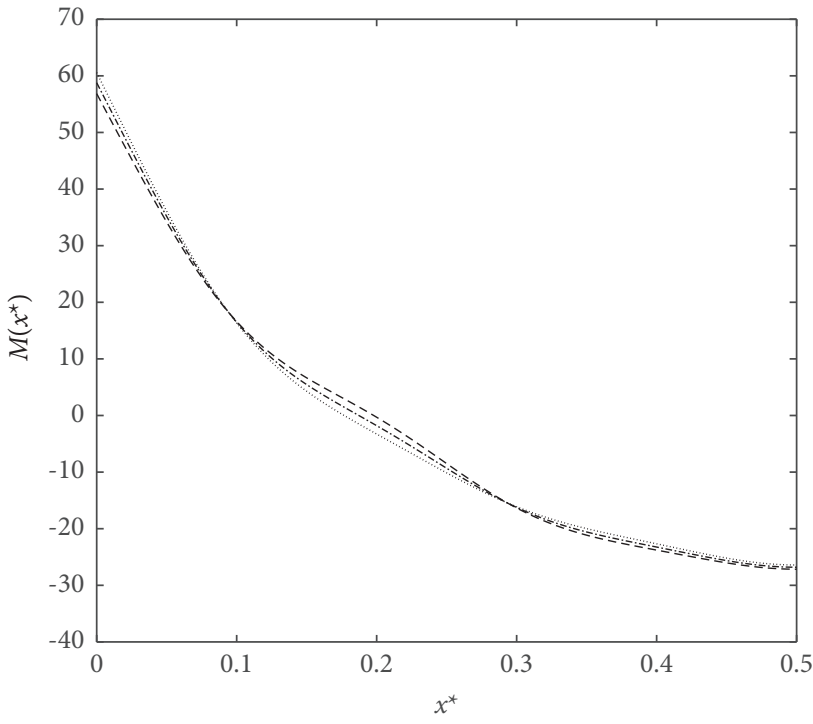

Nonlinear Bending Moment

$$
\begin{aligned}
\text { … } & F^{c}=0 \\
\text {-.- } & F^{c}=100 \\
--- & F^{c}=200
\end{aligned}
$$

FIGURE 20: The linear and nonlinear bending moments of beam (b) with $e=0.1$, for various levels of $F^{c}$.

TABLE 13: Percentage correction between bending moments estimated from the linear and nonlinear theories for beam (b) with $e=0.1$, excited by various levels of $F^{c}$.

\begin{tabular}{lcccc}
\hline & & Bending moment & \\
$F^{c}$ & $x^{*}$ & Nonlinear & Linear & Percentage correction \% \\
\hline \multirow{2}{*}{0} & 0 & 60.57 & 42.18 & 30.35 \\
& 0.5 & -26.40 & -29.94 & 13.40 \\
\multirow{2}{*}{100} & 0 & 58.78 & 39.74 & 32.38 \\
& 0.5 & -26.80 & -30.69 & 14.49 \\
\hline \multirow{2}{*}{200} & 0 & 56.85 & 37.42 & 34.16 \\
& 0.5 & -27.15 & -31.45 & 15.82 \\
\hline
\end{tabular}


higher for beam (b) than for beam (a), but conversely, this percentage is higher for beam (a) than for beam (b) in the middle.

Figure 20 illustrates the effect of varying the force level on the bending moments of beam (b) obtained via linear and nonlinear theories. Three scenarios are plotted for both the linear and nonlinear cases, for a beam (b) with $e=0.1$, $W_{\text {max }}^{*}=2$, excited by a concentrated force located at the middle. For the first one, $F^{c}$ is equal to zero, the second and the third ones correspond to $F^{c}=100$ and $F^{c}=200$. Since the beam considered is symmetrical, the figure presented shows only half of the bending moment distribution. The numerical results of the three scenarios are summarized in Table 13 for two positions: the first being the end of the beam and the second being its middle.

The effect of varying the force level on the linear and nonlinear bending moment distributions is illustrated in Figure 20, and the numerical value of the bending moments is given in Table 13 and their percentage correction. It can be clearly seen that by increasing the level of the force, the percentage correction increases, respectively. However, this change remains small since by varying $F^{c}$ from 0 to 200 , the percentage correction increases only from $30.35 \%$ to $34.16 \%$ for $x^{*}=0$ and from $13.40 \%$ to $15.82 \%$ for $x^{*}=0.5$.

\section{Conclusion}

Geometrically, nonlinear free and forced vibrations of tapered beams have been studied based on Euler-Bernoulli beam theory and von Karman nonlinearity assumptions. Two tapered beams with two steps maintaining a symmetrical shape have been examined. The solution of the linear problem of these beams has been developed and the expressions for the transverse displacement, the bending rotation, the bending moment, and the sheer force have been derived in terms of Bessel functions of order $n$. The end and compatibility conditions have been written in order to calculate the frequencies using the Newton-Raphson algorithm and determine consequently the associated mode shapes. Starting the nonlinear analysis by expanding the unknown displacement functions in the form of a series of the linear mode shapes previously calculated, the discrete expressions for the strain and kinetic energies have been then derived and the nonlinear algebraic system obtained using Hamilton's principle solved by a multimode approach. In order to verify the validity and accuracy of the numerical method proposed, comparisons were made in the linear and nonlinear cases giving a good agreement. The relative difference between the present work and those obtained by the Galerkin method does not exceed $1.9 \%$ for $W_{\max }^{*}=3$. The first results presented focused on geometrically nonlinear free vibrations, in which the effect of the taper and cross section area ratios were presented in backbone curves. It appears that by increasing the taper ratio, the hardening effect also increases, but conversely, increasing the cross section area ratio leads to a reduced hardening effect. The effect of geometric nonlinearity on the dynamics of a tapered beam was also illustrated through bending moment curves for different scenarios derived from linear and nonlinear calculations. The difference between the linear and nonlinear bending moments obtained has been quantitatively estimated via correction percentages. This showed that the use of the linear theory can be misleading because of the significant percentage correction obtained in all of the cases examined and the changes in the maximum bending moment locations obtained via the linear and nonlinear theories. The effect of the taper and cross section ratios on the nonlinear behaviour of tapered beams were illustrated and discussed in the forced case. The geometric nonlinearity caused a hardening effect and the possible occurrence of jump phenomena. In addition, increasing the taper ratio leads to an increase in the nonlinear hardening effect. On the other hand, the increase in the cross section ratio leads to a decrease in the hardening effect. In addition, it was observed that the increase in the maximum nondimensional amplitude or the concentric force leads to an increase in the percentage correction predicted by the nonlinear theory in comparison to the linear theory.

\section{Nomenclature}

\begin{tabular}{|c|c|}
\hline$E:$ & Young's modulus \\
\hline$\rho:$ & Mass density \\
\hline$L_{j}$ : & Length of the $j$-th step \\
\hline$S_{j}$ : & Area at the beginning of each step \\
\hline$I_{j}:$ & Moment of inertia at beginning of each step \\
\hline$S_{j}(x):$ & Cross-section expression \\
\hline$I_{j}(x):$ & Moments of inertia expression \\
\hline$\xi_{j}:$ & Linear variation expression at each step \\
\hline$w_{i}:$ & Linear modes \\
\hline$J_{n}:$ & Bessel functions of the first kind of order $n$ \\
\hline$Y_{n}:$ & Bessel functions of the second kind of order $n$ \\
\hline$I_{n}:$ & $\begin{array}{l}\text { Modified Bessel functions of first kind of } n \\
\text { order }\end{array}$ \\
\hline$K_{n}:$ & $\begin{array}{l}\text { Modified Bessel functions of second kind of } \\
\text { order } n\end{array}$ \\
\hline$N_{x}:$ & Nonlinear stretching forces \\
\hline$T:$ & Kinetic energy \\
\hline$W_{F}:$ & Work done by the external loads \\
\hline$V_{a}:$ & $\begin{array}{l}\text { Energy due to the nonlinear stretching forces } \\
\text { induced by the large deflections }\end{array}$ \\
\hline$W:$ & $\begin{array}{l}\text { Transverse displacement at abscises on the } \\
\text { beam } W(x, t)=w(x) \Phi(t)\end{array}$ \\
\hline$m_{i j}, m_{i j}^{*}:$ & $\begin{array}{l}\text { Dimensional and nondimensional mass } \\
\text { matrices, respectively }\end{array}$ \\
\hline$R_{j}:$ & Length ratio \\
\hline$\alpha_{j}:$ & Taper ratio of the $j$-th step \\
\hline$u_{j}:$ & The cross-sections ratio \\
\hline$v_{j}:$ & Moment of inertia ratio \\
\hline$\beta_{i j}:$ & Eigenvalue parameter of the $j$-th step \\
\hline$z_{j}:$ & Eigenvalue parameter ratio \\
\hline$Y_{i j}(x):$ & Bending rotation of each step \\
\hline$M_{i j}(x):$ & Bending moment of each step \\
\hline $\mathrm{P}_{i j}(x):$ & Shear force of each step \\
\hline$k_{t j}:$ & Linear spring at the end of the $j$-th step \\
\hline$k_{\theta j}:$ & Rotational spring at the end of the $j$-th step \\
\hline$a_{i}:$ & $\begin{array}{l}\text { Contribution coefficients of the } i \text {-th transverse } \\
\text { basic function }\end{array}$ \\
\hline
\end{tabular}




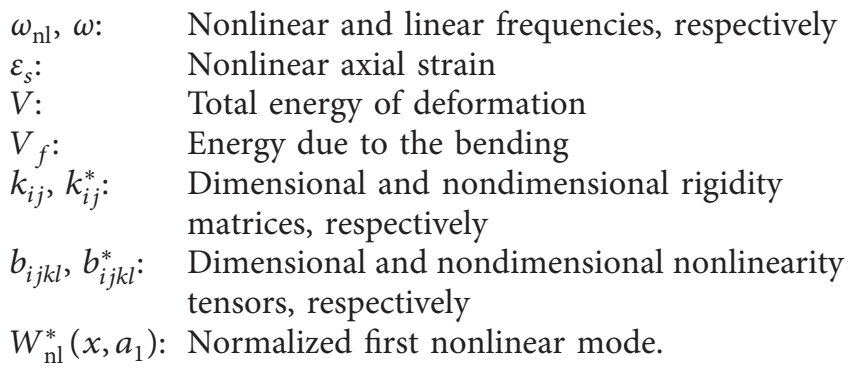

\section{Data Availability}

No data were used to support this study.

\section{Conflicts of Interest}

The authors declare that they have no conflicts of interest.

\section{References}

[1] I. El Hantati, A. Adri, H. Fakhreddine, S. Rifai, and R. Benamar, "A multimode approach to geometrically nonlinear free and forced vibrations of multistepped beams," Shock and Vibration, vol. 2021, Article ID 6697344, 18 pages, 2021.

[2] M. M. Bennouna and R. G. G. White, "The effects the of large dynamic vibration amplitudes of with life on response a clamped-clamped consideration," Journal of Sound and Vibration, vol. 96, 1984.

[3] R. Benamar, M. M. K. Bennouna, and R. G. White, "The effects of large vibration amplitudes on the mode shapes and natural frequencies of thin elastic structures part I: simply supported and clamped-clamped beams," Journal of Sound and Vibration, vol. 149, no. 2, pp. 179-195, 1991.

[4] K. El Bikri, R. Benamar, and M. M. Bennouna, "Geometrically nonlinear free vibrations of clamped-clamped beams with an edge crack," Computers \& Structures, vol. 84, no. 7, pp. 485-502, 2006.

[5] D. J. Sanger, "Transverse vibration of a class of nonuniform beams," Journal of Mechanical Engineering Science, vol. 10, no. 2, pp. 111-120, 1968.

[6] R. P. Goel, “Transverse vibrations of tapered beams," Journal of Sound and Vibration, vol. 47, no. 1, pp. 1-7, 1976.

[7] W. L. Craver and P. Jampala, "Transverse vibrations of a linearly tapered cantilever beam with constraining springs," Journal of Sound and Vibration, vol. 166, no. 3, pp. 521-529, 1993.

[8] S. Abrate, "Vibration of nonuniform rods and beams," Journal of Sound and Vibration, vol. 185, no. 4, pp. 703-716, 1995.

[9] M. A. De Rosa and N. M. Auciello, "Free vibrations of tapered beams with flexible ends," Computers \& Structures, vol. 60, no. 2, pp. 197-202, 1996.

[10] P. A. A. Laura, R. H. Gutierrez, and R. E. Rossi, "Free vibrations of beams of bilinearly varying thickness," Ocean Engineering, vol. 23, no. 1, pp. 1-6, 1996.

[11] N. M. Auciello, "On the transverse vibrations of nonuniform beams with axial loads and elastically restrained ends," International Journal of Mechanical Sciences, vol. 43, no. 1, pp. 193-208, 2001.

[12] J. R. Banerjee, H. Su, and D. R. Jackson, "Free vibration of rotating tapered beams using the dynamic stiffness method," Journal of Sound and Vibration, vol. 298, no. 4-5, pp. 10341054, 2006.
[13] M. C. Ece, M. Aydogdu, and V. Taskin, "Vibration of a variable cross-section beam," Mechanics Research Communications, vol. 34, no. 1, pp. 78-84, 2007.

[14] Y. Huang and X.-F. Li, "A new approach for free vibration of axially functionally graded beams with nonuniform crosssection," Journal of Sound and Vibration, vol. 329, no. 11, pp. 2291-2303, 2010.

[15] M. Taha and M. Essam, "Stability behavior and free vibration of tapered columns with elastic end restraints using the DQM method," Ain Shams Engineering Journal, vol. 4, no. 3, pp. 515-521, 2013.

[16] K. Torabi and H. Afshari, "Free Vibration Analysis of a Nonuniform Cantilever Timoshenko Beam with Multiple Concentrated Masses Using DQEM," Engineering Solid Mechanics, vol. 1, no. 1, 2013.

[17] S. M. Abdelghany, K. M. Ewis, A. A. Mahmoud, and M. M. Nassar, "Vibration of a circular beam with variable cross sections using differential transformation method," Beni-Suef University Journal of Basic and Applied Sciences, vol. 4, no. 3, pp. 185-191, 2015.

[18] F. Sohani and H. R. Eipakchi, "Analytical solution for modal analysis of Euler-Bernoulli and Timoshenko beam with an arbitrary varying cross-section," Math Model Eng, vol. 4, pp. 164-174, 2018.

[19] L. S. Raju, G. V. Rao, and K. K. Raju, "Large amplitude free vibrations of tapered beams," AIAA Journal, vol. 14, no. 2, pp. 280-282, 1976.

[20] K. K. Raju, B. P. Shastry, and G. V. Rao, "A finite element formulation for the large amplitude vibrations of tapered beams," Journal of Sound and Vibration, vol. 47, no. 4, pp. 595-598, 1976.

[21] S. Kumar, A. Mitra, and H. Roy, "Geometrically nonlinear free vibration analysis of axially functionally graded taper beams," Engineering Science and Technology, an International Journal, vol. 18, no. 4, pp. 579-593, 2015.

[22] R. Benamar, M. M. K. Bennouna, and R. G. White, "The effects of large vibration amplitudes on the mode shapes and natural frequencies of thin elastic structures, part II: fully clamped rectangular isotropic plates," Journal of Sound and Vibration, vol. 164, no. 2, pp. 295-316, 1993.

[23] L. Azrar, R. Benamar, and R. G. White, "Semi-analytical approach to the nonlinear dynamic response problem of s-s and $\mathrm{c}-\mathrm{c}$ beams at large vibration amplitudes part I: general theory and application to the single mode approach to free and forced vibration analysis," Journal of Sound and Vibration, vol. 224, no. 2, pp. 183-207, 1999.

[24] L. Azrar, R. Benamar, and R. G. White, "A semi-analytical approach to the nonlinear dynamic response problem of beams at large vibration amplitudes, part II: multimode approach to the steady state forced periodic response," Journal of Sound and Vibration, vol. 255, no. 1, pp. 1-41, 2002.

[25] M. El Kadiri, R. Benamar, and R. G. White, "Improvement of the semi-analytical method, for determining the geometrically nonlinear response of thin straight structures. Part I: application to clamped-clamped and simply supported-clamped beams," Journal of Sound and Vibration, vol. 249, no. 2, pp. 263-305, 2002.

[26] M. El Kadiri and R. Benamar, "Improvement of the semianalytical method, based on Hamilton's principle and spectral analysis, for determination of the geometrically nonlinear response of thin straight structures. Part III: steady state periodic forced response of rectangular plates," Journal of Sound and Vibration, vol. 264, no. 1, pp. 1-35, 2003. 
[27] M. Rougui, F. Moussaoui, and R. Benamar, "Geometrically nonlinear free and forced vibrations of simply supported circular cylindrical shells: a semi-analytical approach," International Journal of Non-linear Mechanics, vol. 42, no. 9, pp. 1102-1115, 2007.

[28] M. E. bekkaye, K. El bikri, and R. Benamar, "Geometrically nonlinear steady state periodic forced response of a clampedclamped beam with an edge open crack," Comptes Rendus Mecanique, vol. 339, pp. 727-742, 2011.

[29] A. Eddanguir, Z. Beidouri, and R. Benamar, "Geometrically nonlinear transverse steady-state periodic forced vibration of multi-degree-of-freedom discrete systems with a distributed nonlinearity," Ain Shams Engineering Journal, vol. 3, no. 3, pp. 191-207, 2012.

[30] L. Boutahar, K. El Bikri, and R. Benamar, "A homogenization procedure for geometrically nonlinear free vibration analysis of functionally graded annular plates with porosities, resting on elastic foundations," Ain Shams Engineering Journal, vol. 7, no. 1, pp. 313-333, 2016.

[31] A. Khnaijar and R. Benamar, "A new model for beam crack detection and localization using a discrete model," Engineering Structures, vol. 150, pp. 221-230, 2017.

[32] H. Moulay Abdelali, K. El Bikri, and R. Benamar, "Analysis of the non linear bending and membrane stresses associated to the fundamental nonlinear mode shape of fully clamped skew plates at large vibration amplitudes," Annals of Solid and Structural Mechanics, vol. 9, no. 1-2, pp. 57-67, 2017.

[33] H. Fakhreddine, A. Adri, and M. Chajdi, "Large Amplitude Forced Vibrations of Restrained Beams Resting on Elastic point Supports," Engineering Transactions, vol. 69, no. 3, 2021,.

[34] J. R. Banerjee and A. Ananthapuvirajah, "Free flexural vibration of tapered beams," Computers \& Structures, vol. 224, Article ID 106106, 2019.

[35] J.-C. Hsu, H.-Y. Lai, and C. K. Chen, "Free vibration of nonuniform Euler - Bernoulli beams with general elastically end constraints using Adomian modified," Journal of Sound and Vibration, vol. 318, no. 4-5, pp. 965-981, 2008.

[36] H. Fakhreddine, A. Adri, S. Rifai, and R. Benamar, "Geometrically nonlinear free and forced vibrations of EulerBernoulli multi-span beams," MATEC Web Conf, vol. 211, 2018.

[37] F. T. K. Au, D. Y. Zheng, and Y. K. Cheung, "Vibration and stability of nonuniform beams with abrupt changes of crosssection by using C1 modified beam vibration functions," Applied Mathematical Modelling, vol. 23, no. 1, pp. 19-34, 1999.

[38] I. El Hantati, A. Adri, H. Fakhreddine, S. Rifai, and R. Benamar, "Geometrically nonlinear free vibrations of fully clamped multi-stepped beams carrying multiple masses," 8th Int. Conf. Comput. Methods Struct. Dyn. Earthq. Eng. Methods Struct. Dyn. Earthq. Eng., pp. 5331-5341, 2021.

[39] C. Johansson, C. Pacoste, and R. Karoumi, "Closed-form solution for the mode superposition analysis of the vibration in multi-span beam bridges caused by concentrated moving loads," Computers \& Structures, vol. 119, pp. 85-94, 2013.

[40] S. Yu and X. Yin, "A generalized superposition method for accurate free vibration analysis of rectangular plates and assemblies," Journal of the Acoustical Society of America, vol. 145, no. 1, pp. 185-203, 2019. 